\title{
Evolution of sexual conflict in scorpionflies
}

2

3 Agnieszka Soszyńska-Maj ${ }^{1}$, Ewa Krzemińska ${ }^{2}$, Ricardo Pérez-de la Fuente ${ }^{3}$, Ji-Shen

4 Wang $^{4}$, Krzysztof Szpila ${ }^{5}$, Kornelia Skibińska ${ }^{2}$, Katarzyna Kopeć $^{2}$, Wiesław Krzemiński ${ }^{2}$ 5

${ }^{1}$ University of Łódź, Faculty of Biology and Environmental Protection, Department of Invertebrate Zoology and Hydrobiology, Banacha 12/16, 90-237 Łódź, Poland. ${ }^{2}$ Institute of Systematics and Evolution of Animals, Polish Academy of Sciences, Sławkowska 17, 31-016 Kraków, Poland. ${ }^{3}$ Oxford University Museum of Natural History, Parks Road, Oxford OX1 3PW, UK. ${ }^{4}$ College of Agriculture and Biological Sciences, Dali University, Dali, 671003, China. ${ }^{5}$ Department of Ecology and Biogeography, Faculty of Biological and Veterinary Sciences, Nicolaus Copernicus University, Lwowska 1, 87-100 Toruń, Poland.

Corresponding authors. E-mail: agnieszka.soszynska@biol.uni.lodz.pl; E-mail: ekrzeminska9@gmail.com

\section{Abstract}

Sexual conflict - opposite reproductive/genetic interests between sexes - can be a significant driver of insect evolution. Scorpionflies (Insecta: Mecoptera) are models in sexual conflict research due to their large variety of mating practices, including coercive behaviour and nuptial gift provisioning. However, the role of palaeontology in sexual conflict studies remains negligible, namely due to the paucity of well-preserved fossils. Here we describe three male scorpionflies from Cretaceous and Eocene ambers. The structure of notal and postnotal organs is analysed in extant and extinct forms; a depression below the base of the notal organ in different panorpid species spatially matches the anterior fold of the female's wing. Based on disparate abdominal configurations and correlations in extant relatives, we posit that each new fossil taxon had a different mating approach along a nuptial giftingcoercive spectrum. The Eocene specimen possesses extreme female clamping abdominal armature, suggesting a degree of sexual coercion greater than in any other known scorpionfly, extinct or extant. The fossil record of abdominal modifications in male scorpionflies documents a relatively late evolution (Eocene) of long notal organs indicating oppressive behaviour toward a female during mating. Our findings reveal a wider array of mating-related morphological specialisations among extinct Panorpoidea, likely reflecting more diversified 
past mating strategies and behaviours in this group, and represent first steps towards gaining a deep-time perspective on the evolution of sexual conflict over mating among insects.

Key words: mating strategies, Mecoptera, amber, Cretaceous, Eocene, new species, new genus, new family

\section{INTRODUCTION}

Sexual conflict between two conspecific sexes arises when divergent interests about the timing and duration of copulation, number of mating partners, or parental investment occur, provided that a trait enhancing the reproductive success ( fitness) of one sex may reduce that of the other (Arnqvist and Rowe, 2005). Currently more broadly defined as the sexually antagonistic selection of shared traits, the sexual conflict is now recognised as a "pervasive evolutionary selective force", leading in many known instances to a male-female coevolution (Parker, 1979; Rostant et al., 2020). At the very core of this conflict lies the struggle for dominance over genetic control in offspring by each sex (Thornhill, 1976, 1979). The study of mating practices offer one of the most direct ways to address sexual conflict in nature. Two seemingly opposite (yet not necessarily mutually exclusive) mating-related strategies are observed in males: aggressive behaviour toward a female, which allows exerting domination while mating, and the nuptial gifting of food to allure and/or pacify a female during the time of copulation and sperm transfer (Lehmann, 2012; McCartney et al., 2013). Both coercive and nuptial gifting strategies appear costly to males because they are based on the differential allocation of limited sources (Liu et al., 2015); therefore, an exaggerated armature may hinder the overall fitness in a male (e.g., in rhinoceros and flour beetles a larger 'weapon' is negatively correlated with wing size; Yamane et al., 2011). In order to incline the female to mate, males show aggression (e.g. calopterygid damselfly; Cordero and Andrés 2002), intimidating behaviour (e.g. water strider; Han and Jabłoński, 2010), and may use special structures, as modified front legs to clasp the female wings (e.g. sepsid flies; Eberhard, 2002) or adhesive discs to secure grip on the female (e.g. diving beetles; Bergsten et al., 2001). Within coercive mating, extreme cases of aggressive behavior by males, which may cause damage or even death to the female, are known among insects and other invertebrate groups, such as true bugs (Siva-Jothy, 2006), water bugs, and camel-spiders (Arnqvist and Rowe, 2002; Hrušková-Martišová et al., 2010) or snails (Kimura and Chiba, 2015), but also among vertebrates (e.g., ducks: Brennan and Prum, 2012). Nuptial gifting is also widespread. Crickets and bush crickets (Orthoptera: Tettigonidea, Grylloidea) provide an edible gift 
attached to a structure containing the sperms. Female consumes the nutritious part during fertilisation by the spermatozoans, the time for consumption correlating with that of fertilisation (Lehmann, 2012; McCartney et al., 2013). Males of other orthopterans offer thoracic secretions (Gryllidae; Bussiére et al., 2005) or even their own hind wings as nuptial gifts (Haglidae; Eggert and Sakaluk, 1994; Sakaluk et al., 2004). Silk-wrapped nuptial gifts of prey are offered by spiders (Stålhandske, 2001) and dance flies (Diptera: Empididae; PrestonMafham, 1999; Sadowski et al., 1999; LeBas and Hockham, 2005); the shining silk cover makes a gift more enticing and may deceive the female if it only contains a scarce - or even fully absent - edible portion (Ghislandi et al., 2017). In dobson flies (Megaloptera: Corydalidae), the species offering nuptial gifts have a 'weapon' armature used for fighting off the rivals smaller than in species whose males rely only (or mostly) on such armature (Liu et al., 2015). Among mecopterans, a gift of prey is offered by hangingflies (Bittacidae; Thornhill, 1976) and scorpionflies (Panorpa spp.; Gwynne, 1984); the latter may offer hardened salivary masses to the female instead (Thornhill, 1979; Bockwinkel and Sauer, 1994). Coercive and nuptial-gifting mating approaches can co-occur in same species, which then exhibits a mixed strategy that can serve as a model to study the trade-off between these two tactics (e.g., Tong and Hua, 2019).

Scorpionflies (Mecoptera: Panorpidae) are models in sexual conflict research. Their mating practices range from coercive to provisioning nuptial gifts, in extreme cases including mouth-to-mouth salivary transfer until the end of copulation (Zhong et al., 2015). Mecoptera are among the oldest holometabolous insects. They are known since the Permian, when they were a significant component of the flying insect fauna. Whereas scorpionflies flourished in the Mesozoic, most of their lineages rapidly declined during the Cenozoic. In fact, mecopterans are considered to have gone through a degree of extinction unparalleled among holometabolans (Grimaldi and Engel, 2005). Extant Mecoptera are classified in nine families, most of which are relict; only two lineages, Panorpidae and Bittacidae, are relatively speciesrich. The Panorpidae appeared in the Late Jurassic (Ding et al., 2014) and currently represent the most diverse mecopteran lineage, with about 480 described species classified in seven genera (Bicha, 2018; Miao et al., 2018), i.e., c. 67\% of extant mecopteran species.

In scorpionfies, the male behaviour towards the female may be coercive in such a degree that the expression 'rape' has been used in the past for describing their mating rituals (Thornhill, 1980). In any case, the role of a female in controlling mating and the eventual reproductive outcome appears more active and decisive than initially thought in the group, namely through precopulatory male choice, struggling behaviour to interrupt genital 
101 connection, and the selective reception of sperm from gift-providing males (likely through spermathecal muscular action; Kock et al., 2009). The modifications of panorpid males enabling coercive mating behaviour include a diverse array of structures on different abdominal segments as well as thinned and elongate last segments of the abdomen. Some of these structures, the so-called notal and postnotal organs, effectively act as a 'clamp', grasping the female's wing prior to and during the course of copulation (Figure 1A and B,

107 Figure 1F). Depending on the size and shape of these organs in a species, the grasp is more or

108 less coercive. Elongate abdominal segments enable the males to bend the abdomen over that 109 of the female, while additional, usually paired abdominal structures referred to as anal horns are used to achieve and maintain the strained, twisted copulatory position of both abdomens

111 for the long time required for sperm transmission, which could be more than three hours

112 (Tong et al. 2018; Tong and Hua, 2019). Panorpid species with very long notal organs, 113 capable of clamping the entire width of the female wing, only use coercion, so no food gifts 114 are offered (Tong and Hua, 2019). In species with mixed strategies, it is the physical 115 condition of the male which determines the followed strategy (Enquist and Sauer, 2001): 116 older and weaker males, as well as smaller ones, primarily adopt an aggressive strategy toward a female, as they are either not able to obtain a prey as a gift or to fabricate it through salivary production, or their gift is often been stolen by a stronger male. Larger males also have an advantage over smaller ones when competing for dead arthropods that can be offered to a female or, if eaten by the male, allow to produce salivary masses. On the other hand, conspecific smaller males bear proportionally larger notal organs (Thornhill, 1990), which shows the genetic background of this negative allometry.

Here we describe three exceptional scorpionflies from three different Cretaceous and

124 Eocene ambers deposits and each belonging to a distinct panorpoid lineage. The disparate abdominal configurations and specialisations in the new taxa allow us to extrapolate trends observed among extant relatives, discussing possible mating habits for the new fossils and previously described ones with preserved non-genitalic abdominal modifications (Willmann and Novokschonov, 1998; Archibald, 2010; Krzemiński and Soszyńska-Maj, 2012; Zhang et al., 2021). Additionally, the new taxa is of general evolutionary significance, including the description of a new extinct panorpoid family and the first orthophlebiid species described in amber. 


\section{Systematic Palaeontology}

136 Mecoptera Packard, 1886

137 Panorpoidea Latreille, 1805

138 Panorpidae Latreille, 1805

139 Baltipanorpa Krzemiński and Soszyńska-Maj, 2012

140 Type species. Baltipanorpa damzeni Krzemiński and Soszyńska-Maj, 2012; Baltic amber.

141 Other species included. Baltipanorpa oppressiva sp. nov.; Baltic amber.

143 Baltipanorpa oppressiva Soszyńska-Maj and Krzemiński sp. nov. (Figures 1A-H)

144 Etymology. After "oppressio", meaning "coercive" in Latin, referring to the most restraining 145 notal organ ever found within Panorpidae. Gender is feminine.

146 Material. Holotype MP/2711, most part of the abdomen and wings preserved,

147 Locality and age. Baltic amber, middle Eocene (ca. $45 \mathrm{Ma}$ ).

148 Diagnosis. Wing membrane with dark maculations (vs. transparent in B. damzeni); notal and 149 postnotal processes very long, reaching end of VII segment, notal process distally forked (vs. 150 notal process shorter than postnotal, and not forked in B. damzeni); abdominal segment $\mathrm{V}$ 151 slightly wider than long; tergite $\mathrm{V}$ medially bearing large, strongly recurved process (vs. 152 tergite $\mathrm{V}$ without process in $B$. damzeni); segments VII and VIII thinned at base, not 153 particularly elongate, about $3-4 \times$ as long as maximal width (vs. segments VII and VIII 154 strongly elongate in $B$. damzeni).

155 Description. Body length $2.2 \mathrm{~mm}$ as preserved (only abdomen). Head. Antennae partly 156 preserved with 14 cylindrical flagellomeres twice longer than wide. Wings (Figure 1A). 157 Elongate and narrow, almost $3.5 \times$ longer than wide, at least $10 \mathrm{~mm}$ long, $\sim 3 \mathrm{~mm}$ wide. 158 Forewing (Figure 1G). Membrane bearing seven maculated areas, largest occupying the wing 159 tip; Sc short and single reaching wing margin in midwing, opposite crossvein m-cu; costal 160 area narrow; $\mathrm{R}_{1 \mathrm{a}}$ and $\mathrm{R}_{1 \mathrm{~b}}$ surrounding pterostigmal area; $\mathrm{Rs}$ with five branches reaching wing 161 margin, $\mathrm{Rs}_{1+2}$ longer than $\mathrm{R}_{3+4}$; fork of $\mathrm{Mb}$ more distal than fork of $\mathrm{Rs}$, crossvein $\mathrm{r}_{3+4}-\mathrm{m}_{1+2}$ 162 sinuous; $M$ with four branches reaching wing margin, $M_{1+2} 13 \times$ longer than $M_{3+4}, M_{4}$ sharply 163 curved at $\mathrm{m}-\mathrm{cu} ; \mathrm{Cu}_{1}$ and $\mathrm{Cu}_{2}$ fused at base, with two crossveins between them; three anal 164 veins, $A_{1}$ reaching wing margin proximal to origin of Rs. Hind wing (Figure $\left.1 \mathrm{H}\right)$. Venation very similar to forewing, except for: $\mathrm{Mb}$ fused with $\mathrm{Cu}_{1}, \mathrm{~A}_{1}$ proximally fused with $\mathrm{Cu}_{2}$, only one cu2-a2. Abdomen (Figure 1A and B). Incomplete, longer than wings; first two segments are missing; notal and postnotal processes on tergites III and IV, respectively (Figure 1B), both processes very long $(1.2 \mathrm{~mm})$, about equal in length, reaching segment VII; notal process 
with spine-like setae on inner surface's distal half (Figure 1B and C), bearing terminal fork curved posteriorly (Figure 1E); postnotal process terminally curved anteriorly, lodged between prongs of notal process (Figure $1 \mathrm{~B}$ and $\mathrm{C}$ ), bearing one very long seta at midlength of organ, and few shorter setae in basal part (Figure 1C and D); postnotal organ covered with short and blunt teeth, irregularly distributed on inner surface; tergite V medially bearing a large, strongly recurved process (horn, $300 \mu \mathrm{m}$ ); abdominal segments VI-VIII moderately elongate, with fused tergites and sternites; segments VII-VIII narrower basally. Genitalia (Figure 1B). Genital bulb round; hypovalves narrow, not extending to apex of gonocoxite; gonostylus shorter than gonocoxite.

\section{Remarks.}

\section{Orthophlebiidae Handlirsch, 1906}

Burmorthophlebia Soszyńska-Maj, Krzemiński and Wang gen. nov.

Etymology. Combination of Burmo-, after Burmese amber, and -orthophlebia, after the genus Orthophlebia (from the Greek "phlebas", $\varphi \lambda \varepsilon \dot{\beta} \beta \alpha \varsigma$, meaning "veins") to emphasize an alleged close relationship to this genus. Gender is feminine.

Type species. Burmorthophlebia multiprocessa sp. nov., by monotypy and present designation.

Diagnosis. Rostrum long and narrow; antenna with at least 30 flagellomeres. Fore- and hind wings with $\mathrm{R}_{1}$ slightly curved in pterostigmal area towards anterior wing margin; Rs with five branches (vs. six and more in other genera of Orthophlebiidae), $\mathrm{Rs}_{1+2}$ and $\mathrm{Rs}_{3+4}$ very long (vs. much shorter in other genera of Orthophlebiidae) $\mathrm{Rs}_{1}$ ascending, $\mathrm{Rs}_{1+2}$ and $\mathrm{Rs}_{2}$ almost at the same level. Forewing with Sc long and simple, reaching pterostigmal area; $\mathrm{M}$ with five branches; two crossveins present between $\mathrm{M}_{4}$ and $\mathrm{Cu}_{1}$; two anal veins. Hind wing with $\mathrm{Sc}$ single and simple, only reaching $\mathrm{M}_{3+4}$ forking; $\mathrm{M}$ with four branches; one anal vein. Abdominal segments VI-VIII moderately elongate; very short notal process on tergite III, not extending beyond end of this tergite; postnotal process absent; two hirsute postnotal areas on tergite IV; tergites VI and VII with a pair of distal appendages each. Genital bulb without stem part, gonostyli long and thin.

Burmorthophlebia multiprocessa Soszyńska-Maj, Krzemiński and Wang sp. nov. (Figures 2A-H)

Etymology. Species name highlights the unusual morphology of the holotype, possessing multiple processes on abdominal segments. 
Material. Holotype MP/3721, male.

204 Locality and age. Kachin amber, Myanmar; earliest Cenomanian (98.8 $\pm 0.62 \mathrm{Ma})$, Late 205 Cretaceous.

206 Diagnosis. As for the genus (vide supra).

207 Description. Body length $9.5 \mathrm{~mm}$ from frons to the end of gonostyli (Figure 2A). Head 208 (Figure 2G). Three occipital bristles; rostrum $2 \mathrm{~mm}$ long, first five flagellomeres only slightly 209 longer than wide, gradually becoming more elongate, distal visible flagellomeres $3 \times$ longer 210 than wide; maxillary palp five segmented, palpomeres slim, ca. $4 \times$ longer than wide. Thorax. 211 Legs with setae arranged in whorls, each bearing a pair of long tibial spurs; fifth tarsomere ca. $2124 \times$ longer than fourth one, two pretarsal claws; first tarsomeres bear, no swellings on any leg. 213 Wings. Proximally narrow and significantly broadening distally, $9.5 \mathrm{~mm}$ long and ca. $3.5 \mathrm{~mm}$ 214 wide; wing membrane bearing a round, dark pigmented spot in medial sector. Forewing 215 (Figure $2 \mathrm{C}$ ). Sc and $\mathrm{R}_{1}$ reaching pterostigmal area, two crossveins between $\mathrm{C}$ and $\mathrm{Sc}$; $\mathrm{Rs}_{1+2}$ 216 almost $3 \times$ longer than $\mathrm{Rs}_{1}, \mathrm{Rs}_{3+4}$ longer than $\mathrm{Rs}_{3}$ and $\mathrm{Rs}_{4} ; \mathrm{M}$ with five branches reaching wing 217 margin, $\mathrm{Mb}$ forking beyond the $\mathrm{Rs}$ fork, $\mathrm{M}_{1+2} 9 \times$ longer than $\mathrm{M}_{3+4}, \mathrm{M}_{4 \mathrm{a}+\mathrm{b}} 3.5 \times$ longer than $218 \mathrm{M}_{3+4}$; two $\mathrm{m}_{4}-\mathrm{cu}_{1}$ crossveins, the most proximal slightly bending $\mathrm{M}_{4}$; two crossveins between $219 \mathrm{~A}_{1}$ and $\mathrm{A}_{2}, \mathrm{~A}_{3}$ not visible. Hind wing (Figure 2D) same as in forewing; $\mathrm{Mb}$ fused with $\mathrm{Cu}_{1}$; 220 second anal vein reduced or invisible. Abdomen (Figure 2E and F). Elongate, notal organ on 221 abdominal tergite III wide at base and curved toward distal part; postnotal organ on tergite IV 222 acutely elevated, composed of two areas of dense brush of short setae, distal part of tergite IV 223 curved upward and covered with dense setation (Figure $2 \mathrm{H}$ ); abdominal segment $\mathrm{V}$ ca. 1/3 224 longer than wide; segment VI ca. $1 / 2$ longer $(800 \mu \mathrm{m})$ than wide, bearing a pair of relatively 225 large anal horns on posterior margin of tergum; distinct sinuous seam between tergites and sternites (Figure 2E and F); tergites and sternites VII-VIII fused; segment VII (1.3 mm) distinctly thinned at base and gradually broadening distally, horns on posterior tergum 228 margin, opposite to them the sternite bears a process with dense setae; segment VIII ca. $2 \times$ 229 longer than wide, sternite covered with setae. Genitalia. Genital bulb narrow (Figure 2E); 230 gonostyli longer than gonocoxites, very thin at apex, covered with numerous setae; hypovalve 231 broad; epandrium most likely with two processes.

232 Remarks. Burmorthophlebia gen. nov. differs from all other genera of the family 233 Orthophlebiidae in number of veins in radial sector, and in unusually long veins $\mathrm{Rs}_{1+2}$ and $234 \mathrm{Rs}_{3+4}$ which are only terminally forked, at level of end of Sc. Wings of Burmorthophlebia are 235 more narrow than in other orthophlebids. Five veins in radial sector are present also in a 236 recently established family Protorthophlebiidae (Soszyńska-Maj et al., 2020), but the rostrum 
in this family is short (only c. twice as long as its maximum width), and VI-VIII abdominal segments in male are shorter than wide, while Burmorthophlebia has a long rostrum and elongate abdominal segments, both characters typical to orthoplebids.

241 Cantabridae Soszyńska-Maj, Pérez-de la Fuente, Krzemiński and Wang fam. nov.

242 Type genus. Cantabra gen. nov., by monotypy and present designation.

243 Diagnosis. Head with three pairs of long ocellar bristles, rostrum elongate; pronotum 244 elongate, longer than head, bearing long bristles; Sc single, costal area narrow, R and M sectors with four branches in both wings, crossvein cu2-a2 present in hind wings; male abdomen much longer than wings, with elongate and narrow segments VI-VIII, tergites and sternites VII and VIII fused; male gonostylus without median tooth, with several minute denticles.

249 Remarks. The wing venation and general habitus of Cantabra gen. et. sp. nov. resemble 250 those of the Panorpidae and Panorpodidae. The new fossil species differs from panorpids in 251 the distinct body bristles, particularly those on head and thorax, an unusually elongate 252 pronotum, clearly longer than the head (shorter in panorpids), and the lack of median tooth on 253 the inner surface of male gonostyli, instead bearing several minute denticles in a row. From 254 panorpodids, Cantabra gen. et. sp. nov. differs in greatly elongate rostrum, elongate abdomen and fused VII and VIII abdominal segments. The remarkably elongate and narrow male abdomen of the new taxon resembles extinct family Holcorpidae, but differs from the latter in five veins in medial sector in both wings and less elongate abdominal segments VI-VIII 258 (Archibald, 2010).

260 Cantabra Soszyńska-Maj, Pérez-de la Fuente, Krzemiński and Wang gen. nov.

261 Type species. Cantabra soplao sp. nov., by monotypy and present designation.

262 Etymology. After the Latin "cantabra" ("cantabrum" in masculine) meaning "from, or 263 pertaining to, Cantabria" - i.e., the Autonomous Community of Spain where the El Soplao 264 outcrop is located. Gender is feminine.

265 Diagnosis. As for the family (vide supra).

267 Cantabra soplao Soszyńska-Maj, Pérez-de la Fuente, Krzemiński and Wang sp. nov. (Figures $2683 \mathrm{~A}-\mathrm{G}$ and Figures $4 \mathrm{~A}-\mathrm{E})$

269 Etymology. After the El Soplao amber outcrop, where the amber inclusion was found. The specific epithet is treated as a noun in apposition. 
Material. Holotype CES-437, male.

272 Locality and age. El Soplao amber outcrop; middle Albian, Early Cretaceous (ca. 105 Ma).

273 Diagnosis. As for the genus (vide supra).

274 Description. Body length $\sim 9.25 \mathrm{~mm}$ without antennae (Figure 3A). Head (Figures 3B and C).

275 Rostrum with preserved proximal part about $1.5 \times$ as long as that of head; 20 flagellomeres 276 preserved, all elongate, $2-3 \times$ as long as wide, covered with microsetae; three pairs ocellar 277 bristles on vertex, $\sim 350 \mu \mathrm{m}$ long, probably surrounding ocelli (the latter not discernible). 278 Thorax. Pronotum with long bristles, 300-350 $\mu \mathrm{m}$ long; only one right foreleg partially 279 preserved, elongate, rather delicate, bearing microsetae on its entire length; femur bearing 280 ventral bristles; tibiae with a few whorls of spike-like setae arranged in whorls and bearing two long spurs distally. Wings. Only right wings fully preserved. Wings elongate and narrow, almost $4 \times$ longer than wide, $6.5 \mathrm{~mm}$ long, $1.7 \mathrm{~mm}$ wide; $\mathrm{C}$ covered with setae, longer and thinner in anal region. Forewing (Figure 4A). Costal area narrow, with Sc unbranched and long, reaching wing margin opposite tip of $\mathrm{M}_{4} ; \mathrm{R}_{1}$ faint, its two branches surrounding pterostigmal area; radial sector with four branches; $\mathrm{Rs}_{1+2}$ almost twice as long as $\mathrm{Rs}_{3+4} ; \mathrm{M}_{1+2}$ almost $7 \times$ longer than $\mathrm{M}_{3+4} ; \mathrm{Cu}_{1}$ and $\mathrm{Cu}_{2}$ fused at base; three anal veins present, $\mathrm{A}_{1}$ reaching the wing margin beyond fork of Rs; short spines along anal veins and wing membrane on anal area; jugal area with few long bristles. Hind wing (Figure 4B). Venation mostly similar to that of forewing, except short Sc, not reaching beyond the level of end of $\mathrm{Cu}_{1} ; \mathrm{R}_{1}$ forking at the level of end of $\mathrm{Cu}_{1} ; \mathrm{Mb}$ fused with $\mathrm{Cu}_{1} ; \mathrm{A}_{1}$ proximally fused with $\mathrm{Cu}_{2}$ and reaching wing margin only slightly beyond fork of Rs; one crossvein between $\mathrm{Cu}_{2}$ and $\mathrm{A}_{2}$; crossveins hardly visible. Abdomen (Figure 4C). Significantly longer than wings; tergite III not visible dorsally, notal organ not discernible, but (if present) not long, (otherwise it would be visible above tergite IV); small postnotal organ present on tergite IV; long bristles on sternites IV-V; abdominal segments VI to VIII elongate and narrow, segment VI (1.8 mm long) 7× longer than wide, segment VII $(1.4 \mathrm{~mm}) 6 \times$ longer than wide, segment VIII $(1.5 \mathrm{~mm}) 10 \times$ longer than wide; segment VI most probably with a fusing seam; segments VII and VIII with tergites and sternites fused. Genitalia (Figure 3F and G, 4C and D). Genital bulb elongate, hypovalves probably broad, not extending to apex of gonocoxites; gonostyli (1 mm) longer than gonocoxites $(700 \mu \mathrm{m})$, slender, inwardly curved at apex, without median tooth, and with rounded and relatively small basal processes; inner margin of gonostylus with at least eight short triangular denticles in a row along median and basal parts; basal processes of parameres long and curved ventrally, with their basal branch rounded, covered with dense microsetae reaching apex of gonocoxite, hypovalve probably broad. 


\section{DISCUSSION}

A series of clamping devices used to seize and hold different body parts of the female during courtship and copulation exist in panorpid males. These structures ensure the eventual genital connection and sperm transfer; and extend copulation time (Zhong and Hua, 2013; Zhong et al., 2014). The latter is critical for males, as the more prolonged the copulation, the more sperm can be transferred and, thus, the greater the number of potentially fertilised eggs (Engqvist and Sauer, 2001; Kullmann and Sauer, 2005). Aside from genital clamping structures (among which the most conspicuous is a pair of pincer-like gonostyli), panorpids present non-genital clamping systems on their abdomens. These are notal and postnotal organs, as well as anal horns which are used to catch and immobilize female during mating. Based on the size, shape and interlocking mechanism of these clamping structures, the grasp on the body of female becomes more or less secure, therefore facilitating a greater degree of coercion during mating, which has been associated with less investment in costly nuptial gifts (Tong and Hua, 2019).

\section{Notal and postnotal organs}

The notal organ (NO) is a process on abdominal tergite III. The postnotal organ (PO) typically consists of a small process on abdominal tergite IV (Crampton, 1931; Mickoleit, 1971b). In extant scorpionflies, both structures are present in most Panorpidae, in one and the only recent species from the Eomeropidae (the 'living fossil' Notiothauma reedi MacLachlan, 1877; Crampton, 1931), and can be vestigial, if present, in the Panorpodidae (Tong et al., 2017; Wang and Hua, 2018a). Both NOs and POs act jointly by typically creating a clamping structure that grasps the female forewing before and during copulation; in panorpids, these organs allow to achieve and maintain the typical V-shaped mating position (Figure 6A and B) (Byers and Thornhill, 1983). Moreover, the NO and the PO bear specialised setae, cephalically directed and thinned terminally, which interlace and/or electrostatically interact with both venational setae and membrane microtrichia from the female's wing (Zhong and Hua, 2013). Observations on three species of Neopanorpa van der Weele, 1909 bearing NOs of different lengths have shown different mating strategies in these species (Zhong and Hua, 2013; Tong and Hua, 2019). Males of two species with short and medium-sized NO (i.e., $N$. lui Chou and Ran, 1981 and N. carpenteri Cheng, 1957, respectively) indirectly transfer a 
of the PO, and the medium sized $\mathrm{NO}$ in $N$. carpenteri reaches the end of the abdominal segment IV; both stabilize the female wings only partially and apparently play an auxiliary role during copulation. Contrarily, $N$. longiprocessa Hua and Chou, 1997, with a long NO capable to cover and keep the entire wing width of the female, exclusively relies on coercive copulation, and does not offer nuptial gifts. Short NOs and POs pinch only the anterior margin of female forewings, and both processes are spatially suited to fit the latter. In Panorpa amurensis MacLachlan, 1872 (Figures 5A and B), the space created by the clasped NO and PO matches the space of the anterior valley fold of the female wing delimited by the convex costal vein $(\mathrm{C})$, the concave subcostal vein $(\mathrm{Sc})$, and the convex radial vein $\left(\mathrm{R}_{1}\right)$, clamping together with the PO before or at the latter vein. Our measurements of these distances in this and other panorpid species with various NOs indicate that this seems to be an effective arrangement to grip the anterior wing fold of the female (see Supplementary File 1 for measurements). As the $\mathrm{C}, \mathrm{Sc}$, and $\mathrm{R}_{1}$ run almost parallel over a long stretch, the female forewing may be gripped more anteriorly or posteriorly, usually by its half or basal third, as can be observed in photographs of mating panorpids (Zhong and Hua, 2013; Zhong et al., 2014; Tong and Hua, 2019).

A short NO of the type similar to that in Recent panorpids was already present among the Late Jurassic panorpoids, as evidenced by Orthophlebia heidemariae Willmann and Novokschonov, 1998 (Figure 6C and D). This species is currently classified in Orthophlebiidae, a Mesozoic polyphyletic panorpoid assemblage ancestral to Panorpidae (Soszyńska-Maj et al., 2020). In Burmorthophlebia multiprocessa gen. et sp. nov. the NO, although also short, differs from all the hitherto known in Mecoptera, extinct or extant. The NO is distinctly raised over abdomen but poorly pronounced, not reaching any process to form a clamp with. The PO is here replaced by two elevated areas on tergite IV, the postnotal areas 1 and 2 (PA1 and PA2; Figure 5E). The former is mound-like, located after an anterior depression on tergite IV and at a distance from the NO comparable to that of $\mathrm{C}$ to $\mathrm{R}_{1}$. The PA2 is sharply elevated, and measurements show that it contacted the female wing just at or slightly beyond the concave radial sector vein (Rs). Both PAs were involved in adhering the female's wing as indicated by their location and specialised setation, consisting of short and dense tufts of hairs different from other abdominal bristles. Apparently, only the costal vein and a brief anterior wing membrane portion were covered by the NO in B. multiprocessa, and so the remaining portion of the female wing was to a certain degree immobilised by the setation of both PAs. Among the extant panorpids the hirsute PAs, more flattened than those of Burmorthophlebia and situated on three consecutive tergites, have been described in 
Neopanorpa setigera Wang and Hua, 2018 and N. luojishana Wang and Hua, 2019 (Wang and Hua, 2018b, 2019b), and also exist in N. longistipitata. However, in these species the NO is long and able to keep the entire wing of a female pressed against the male's abdomen to a lesser or greater extent, so the hirsute PAs are probably only of auxiliary importance (Figures 6A-D). This contrasts with the armature in B. multiprocessa gen. et sp. nov., where it was the interaction between NO-PO setae and the integumentary structures of the female's wing that kept a larger portion of the latter in place, although the fixing must have been weaker. Recent panorpids with a short NO (and anal horns) adopt a mixed mating strategy (Neff and Svenson, 2013). After a courtship ritual, males present nuptial gifts to the female, but if they are not able to get one ready (including if they have been stolen by other males) or the gift is deemed as unsatisfactory by the female (e.g., small salivary secretions due to poor condition of the male), they resort to attempt coercive copulation (Thornhill and Sauer, 1991). Baltipanorpa multiprocessa, with its short NO and no other armature to immobilize the female's wing, probably had a similar approach when mating.

As introduced above, long NOs differ mechanically from short NOs. They are present in a small group of species classified in the genera Panorpa and Neopanorpa (Hu et al., 2015; Tong and Hua, 2019; Wang and Hua, 2018a). Instead of a pincer-like clamp composed by a PO and NO, the long NO covers the entire female's wing across its full width and immobilizes it more or less pressed against the abdomen. As the mating couple of $N$. longistipitata shows (Figures 6A-D), the leading edge of the female wing is also accommodated in a small depression of tergite IV under the base of the NO. As can be deduced from measured distances, of the three hirsute PAs on tergites IV-VI the first one supports the wing fold by the convex $\mathrm{R}_{1}$; the more distal part of the wing is pressed against the abdomen by the long NO with the help of special muscles (Thornhill, 1990). The tip of the NO is locked between the genital hypovalvae. Although this conformation fully encloses the female wing during mating, the resulting grip is likely not particularly tight. In any case, nuptial gifts are not offered prior or during the mating of Neopanorpa species with a long NO, such as $N$. longiprocessa (Zhong and Hua, 2013), which would suggest that such process enables highly coercive mating behaviour.

Among extinct mecopterans, an extremely long NO was hitherto only known in Baltipanorpa damzeni from Baltic amber (Krzemiński and Soszyńska-Maj, 2012). In this species, the NO forms together with an unusually elongate PO a clip-like structure able to reach beyond the full width of the female's wing during mating (Figures 6E). Both NO and PO possess short tooth-like bristles, which would have increased their holding power. The PO 
406 is bent anteriorly, partially securing the clip in this way. Baltipanorpa oppressiva sp. nov has

407 a similarly characteristic NO-PO clip bearing inner tooth-like bristles, but its NO is terminally 408 forked in two prongs bent posteriorly at an almost right angle, which embrace the tip of PO 409 (Figure 1B and E, Figure 6F). The interaction of these structures in the new species results in 410 a full clasp-like mechanism. The female wing enclosed in this remarkable clamp was likely 411 fully immobilised, a withdrawal attempt probably causing risk of tearing the wing membrane. 412 A similar function, although less effective than that in B. oppressiva sp. nov, must have been 413 accomplished in B. damzeni by a few pairs of elongate bristles on the posterior side of the NO 414 (Figure 6E). Furthermore, the NO-PO clamp in Baltipanorpa is raised at angle of about $50^{\circ}$ 415 from the abdomen, and so the captured female's forewing was also kept raised and separated 416 from the male's abdomen. This position is deemed as genuine (not preservational) as it is now 417 known from two different species (Figure $6 \mathrm{E}$ and $\mathrm{F}$ ) and is unique to this genus. In extant 418 panorpids with very long NOs (Neopanorpa), this process is placed at a much lower angle and 419 keeps the female wing rather flat against the abdomen, having no other counterpart such as the long PO in the two fossil Baltipanorpa species discussed herein (Figure 6A and D).

\section{Anal horns}

The anal horns are distal processes directed posteriorly on abdominal tergite VI. Among extant panorpids, anal horns are single (in Cerapanorpa Gao, Ma and Hua, 2016, Megapanorpa Wang and Hua, 2018, and some species of Panorpa Linnaeus, 1758) or paired (Dicerapanorpa Zhong and Hua, 2013), and arise at different angles from the dorsal end of tergite VI (Zhong et al., 2014; Tong et al., 2018; Wang and Hua, 2019a). Aside from panorpids, anal horns are also known in Notiothauma reedi (Eomeropidae; Crampton, 1931; Mickoleit, 1971). In conjunction with tergite VII, which is proximally narrowed and/or depressed, the anal horns create a clamping system to accommodate and hold the female's terminal abdomen into the strained copulatory position necessary for sperm transmission. It has been demonstrated that anal horns play an important role at initiating copulation and in prolonging its duration in the absence of nuptial gifts and under female resistance, and that the lack of anal horns is correlated with the inability to prolong copulation after gift provisioning (Zhong et al., 2014).

Burmorthophlebia multiprocessa gen et sp. nov. bears a pair of anal horns raised at a $45^{\circ}$ angle (Figure 2E and F, Figure 5E). By comparison with extant species, these processes must have been involved in manipulating and holding the female abdomen during mating. Paired anal horns in other fossil species are known in Orthophlebia longicauda Willmann \& 
Novokshonov 1998 (Orthophlebiidae; Late Jurassic of Karatau in Kazakhstan) and in two species of Holcorpa (Holcorpidae) from two Eocene localities (Florissant, Colorado, USA, and the Okanagan Highlands, British Columbia, Canada) (Willmann and Novokschonov, 1998; Archibald, 2010).

\section{Other mating-related modifications in males}

Aside from notal-postnotal organs and anal horns, other male abdominal processes involved in the physical interaction with the female during mating are occasionally present in scorpionflies. Among extant panorpids these are positioned on the ventral side, such as a long process on abdominal sternite III (Neopanorpa furcata (Hardwicke, 1825)) and a 'ventral hook' on sternite VI (Leptopanorpa linyejiei, Wang and Hua, 2020). In fossil panorpoids, other male abdominal structures with assumed clamping function occurred in the Late Jurassic species Orthophlebia heidemariae Willmann and Novokschonov, 1998. This was the case of a large medial horn-like process on tergite V (Figure 5C and D). Such process has been referred to as "tergal spine", "unpaired median tergal process (monocornus)", or a “median tergal horn" (Crampton, 1931; Mickoleit, 1971; Willmann and Novokschonov, 1998, respectively). It is probable that this process was also used to fix the female abdomen during mating in conjunction with other more distal structures from the male dorsal abdomen. The abdomen of $O$. heidemariae is preserved in an upturned position and forming a full circle (Figure 5C), which is a frequent mating position among panorpid males. The large horn-like process is opposite to a small putative process and notch on tergite VII (Figure 5D); both structures likely interlocked with one another to facilitate a strained copulatory position (Willmann and Novokschonov, 1998). In Baltipanorpa oppressiva sp. nov. the horn-like process on tergite $\mathrm{V}$ is strongly recurved, and the subsequent tergite VI has an anterior depression and a greatly expanded end, resulting in a notched shape. Both specialised shapes strongly suggest that this horn and the tergite VI were engaged in holding the female abdomen during mating (Figure 6F). Such conformation was enabled to a certain extent by the position of the female's wings (at least a forewing) which was raised high $\left(56^{\circ}\right)$ over the male's abdomen and secured in this position by the extremely long notal-postnotal clip unique to Baltipanorpa. Moreover, Burmorthophlebia multiprocessa gen. et sp. nov. bears paired processes directed posteriorly at $45^{\circ}$ angle on tergite VII, similar to the paired anal horns

471 present on tergite VI, but smaller. Alleged homologous structures have been formerly referred 472 to as "paired tergal processes (bicornua)" or "lateral tergal horns" (Crampton, 1931; 
473

474

475

476

477

478

479

480

481

482

483

484

485

486

487

488

489

490

491

492

493

494

495

496

497

498

499

500

501

502

503

504

505

Mickoleit, 1971). The most plausible function for these processes in this new species was also holding the female terminal abdomen during mating.

Cantabra soplao gen et sp. nov. has greatly elongate abdominal segments VI-VIII. Among extant panorpids, such development is present in species of Leptopanorpa MacLachlan, endemic to Indonesia, and also in a few Neopanorpa species (Wang and Hua, 2020). Although biology of these taxa remains unknown, the greatly elongate abdomens are considered to be influenced by sexual selection, in displays to females and competition among male rivals. Extremely elongate abdomens were also present among other extinct panorpoid lineages: the Orthophlebiidae (Willmann and Novokschonov, 1998), the Holcorpidae (Archibald, 2010; Li et al., 2017; Zhang et al., 2021), and in taxa of uncertain relationships from the Middle Jurassic of China, where abdomen elongation was extreme (Wang et al., 2013). Great abdominal elongation is regarded as a result of convergence (Wang and Hua, 2020). Additionally, in the Holcorpidae and Orthophlebiidae swellings on the first tarsomeres of the hind legs in males were most probably used in sexual display; the size and shape of these swellings was likely species specific (Zhang et al., 2021). In the mecopterans presented herein the tarsomeres were not modified (yet in Cantabra soplao gen. et sp. nov. the shape of legs is unknown). Tarsal swellings do not occur in Recent Panorpoidea.

\section{CONCLUSIONS}

The morphology of the male's abdomen in extant scorpionflies represents a good approximation to the mating strategy used toward a female. Thus, the abdominal structures of fossil specimens have the ability to convey information on the likely reproductive strategies of extinct scorpionflies and, to some extent, on their evolution. Based on the disparate male abdominal shapes of the three fossil taxa described herein, these almost certainly had different mating strategies along a nuptial gifting-coercive gradient as observed among their extant panorpid relatives. Firstly, the Cretaceous species Cantabra soplao gen. et sp. nov., currently the only known member of its lineage, bears a small PO, with the absence of other posterior abdominal processes. This suggests that its mating behaviour was devoid of coercion and that nuptial gifting must have played an important role in these scorpionflies. Extant panorpid species which NO-PO system is very small or even absent and lack posterior abdominal processes ('horns') either rely on nuptial edible gifts or on mouth-to-mouth feeding during copulation adopting an O-shaped position instead of the typical V-position (Fig. 6; Zhong et al., 2015). It is plausible that the mating in C. soplao was similar. Regardless, the great degree 
of elongation of the abdomen in this species was probably involved in sexual selection dynamics.

Secondly, the Cretaceous Burmorthophlebia multiprocessa gen. et sp. nov., the only orthophlebiid specimen described from amber to date, likely exhibited a mixed mating strategy involving both nuptial gifting and coercive behaviour, as observed in some extant Panorpidae species. This inference is based on a weak notal-postnotal clamping system and two sets of paired processes on the abdomen, which likely ensured female restraint and probably extended copulation beyond any possible nuptial gift stages. Noteworthy, abdominal processes are exceptionally abundant in this species, on the dorsal and ventral sides. Such armature is unknown among extant Panorpidae, and can be compared only with that of Nothiotrauma reedi of the relict family Eomeropidae.

Lastly, in the Eocene Baltipanorpa oppressiva sp. nov. the NO-PO wing clamp, which resembled a sealing clip, was able to tightly grasp the full wing width of the female. Unlike its previously known congeneric relative $B$. damzeni, this structure bore a sophisticated terminal clasp. Together with a highly recurved abdominal horn in this new species, these traits represent the most extreme set of female clamping devices known among scorpionflies, both extinct or extant. Consequently, a fully coercive mating strategy was likely dominant, even exclusive, in this species. During copulation, the female wings (at least the forewings) were likely kept in the notal-postnotal clamp well raised over the male abdomen, this way being separated from the male's anal horn, which is positioned more proximally in this species (i.e., on tergite V vs. in tergite VI in other panorpids). This inclined position of the female's wing(s) enabled the entrapment of her abdomen by the male's anal horn during mating. In evolutionary terms, the fitness costs of such organs and the resulting coercive mating behaviour might have been too high for Baltipanorpa. The very long notal and postnotal processes (Figure 6E and F) raised over the male's body might have hindered flight ability; moreover, because of their size (and perhaps their permanently raised position) these processes were likely prone to injury and thus they might entailed a risk for their bearers. These factors might have contributed to the extinction of Baltipanorpa and its singular morphology, so that the evolution of this extreme clamping device resulted in a blind alley. Moreover, the biology of the female could have also contributed to this extinction if the mating became too oppressive or dangerous, related to the risk of tearing the wing membrane with the teeth and hard bristles of the male's notal organ.

The remarkable diversity of abdominal configurations shown herein suggests that panorpoid mecopterans had accordingly disparate mating strategies and behaviours in the 
past. Data based on fossil and extant species suggest that the coercive mating behaviour in 541 this group is secondary (derived) from the habit of nuptial gifting. According to the current 542 fossil record, long notal organs did not evolve prior to the Eocene (Fig. 7; Supplementary File 543 2). Data from extant mecopterans point at the Choristidae as the sister group of Panorpoidea 544 (Willmann, 1989; Wang and Hua, 2021), which lack notal organs or other abdominal 545 modifications (including elongate distal segments) and adopt an O-shaped mating position 546 while the male transfers mouth-to mouth salivary secretion to the female (Zhong et al., 2015). 547 Hence, it is assumed that the latter condition is likely plesiotypic for Panorpoidea. Our data provide first steps towards gaining a deep-time perspective able to inform discussions on the evolution of mating-related sexual conflict in Mecoptera and in insects more generally. Extant fauna show that extreme female holding mechanisms such as those from Baltipanorpa did not survive until today among scorpionflies (Wang, 2020). In fact, mating strategies involving gift provisioning appear to have been evolutionarily favored among mecopterans contrary to forced mating, and likely more prone to promote the species' genetic diversity. In order to start formulating hypotheses about when mating strategies including those fully coercive- and associated anatomical structures of scorpionflies appeared throughout evolutionary history, it will be necessary to keep discovering fossil males with good abdominal preservation. The latter will in turn necessitate from improving the knowledge on the currently contentious phylogenetic relationships among mecopteran groups.

\section{MATERIALS AND METHODS}

\section{Geological context}

562 The geographical provenance of the amber samples used in this study is marked on the map provided (Figure 8). The Spanish amber sample was gathered in official excavations with the participation of one of us (RPF) taking place between 2008 and 2010 in the El Soplao outcrop (near Rábago village, Cantabria, northern Spain) (Najarro et al., 2009; Najarro et al., 2010), and is dated as middle Albian, Early Cretaceous (ca. 105 Ma) (Barrón, pers. comm.). The Myanmar amber sample comes from Kachin, near Tanai town, Hukawng Valley, Kachin

568 State, Myanmar, and is dated as earliest Cenomanian (98.8 $\pm 0.62 \mathrm{Ma}$ ), Late Cretaceous (Shi 569 et al., 2012). It was acquired in 2016, prior to the armed conflict and the escalation of the ethnic strife in the area (Haug et al., 2020; Szwedo et al., 2020). The age of Baltic amber is estimated as Lutetian, middle Eocene (ca. 45 Ma) (Grimaldi and Ross, 2017), or as late 


\section{Specimen repository}

575 All the studied specimens are deposited in public institutions. Holotype CES-437 is deposited 576 at the Institutional Collection from the El Soplao Cave (Government of Cantabria), Celis, 577 Cantabria, N Spain. The specimen is partly preserved, the amber piece was polished and 578 included in Epoxy resin for visibility and protection. Holotype MP/3721 is housed at the 579 collection from the Museum of the Institute of Systematics and Evolution of Animals, Polish 580 Academy of Sciences, Kraków, Poland (ISEA PAS). The specimen is almost complete, several cracks cut the specimen. Holotype MP/2711 is housed at the collection of the Museum of the ISEA PAS, Kraków, Poland. The specimen is well preserved but incomplete, a neuropteran and a cecidomyiid dipteran are present as syninclusions.

\section{Methods}

586 Photographs of amber inclusions were taken with a Leica M205C stereomicroscope and an attached Leica DFC295 camera, under a Nikon Eclipse E100 compound microscope with an attached Nikon DS F11 camera at the University of Łódź, and with a Nikon SMZ25 stereomicroscope equipped with a Nikon DS-Ri2 digital camera at the ISEA (PAS). In most instances, incident and transmitted light were used simultaneously. Stacks of photographs were processed using NIS-Elements Imaging Software. Drawings were obtained based on the photographs but corroborating the morphological details under the optic equipment, and then digitally processed in CorelDraw X10.

Adult extant scorpionflies were caught by one of us (J.W.) with a collecting net and then preserved in $95 \%$ ethanol or pinned. These specimens are deposited at the Biological Science Museum, Dali University (DALU), Yunnan Province, China. Photographs of the insects were taken with a Nikon D7000 digital camera with a Nikkor AF-S Micro 105 mm f/2.8 lens. The figured specimens of Panorpa amurensis were collected by Sigitas Podenas in South Korea in 2014, and are deposited at the collection of the Department of the Invertebrate Zoology and Hydrobiology, University of Lodz, Poland.

Maps were built using the app Maps-For-Free (https://maps-for-free.com) and modified with the software programs Corel Draw and Corel Photopaint X7. 
606 R1, first radial vein; Rs, radial sector vein; Sc, subcostal vein. Other abbreviations used in 607 figures appear in their respective captions.

\section{Acknowledgements}

609 We express our gratitude to the Editor and four Reviewers for the extensive comments. We 610 thank the El Soplao Cave for providing access to the Spanish amber specimen. Drs Enrique 611 Peñalver and Xavier Delclòs are thanked forfor managing the loan of that specimen and 612 providing support and discussions, and Rafael López del Valle for its preparation. Funding: 613 The research was supported by the grants from the Polish National Science Center (grants No. 614 2013/09/B/NZ8/03270, and No. 2016/23/B/NZ8/00936), and by the University of Łódź, 615 Poland. This study is a contribution to the project AEI/FEDER, UE CGL2017-84419 funded 616 by the Government of Spain and the European Union. JSW is funded by the Starting 617 Foundation for the High-level Talents, Dali University (Grant number KY2096124040) KSZ 618 is funded by Polish National Science Center (grants No. 2018/31/B/NZ8/02113). Competing 619 interests: The authors declare that they have no competing interests. Data and materials 620 availability: All data needed to evaluate the conclusions in the paper are present in the paper 621 and/or the Supplementary Materials. Investigated fossils are available in public institutions.

622

623

\section{REFERENCES}

Archibald B. 2010. Revision of the scorpionfly family Holcorpidae (Mecoptera), with description of a new species from Early Eocene McAbee, British Columbia, Canada. Annales de la Société entomologique de France 46: 173-182. DOI: http://dx.doi.org/10.1080/ 00379271.2010 .10697654

Arnqvist G, Rowe L. 2002. Correlated evolution of male and female morphologies in water striders. Evolution 56: 936-947. DOI: http://dx.doi.org/10.1111/j.0014-3820.2002.tb01406.x.

630 Arnqvist G, Rowe L. 2005. Sexual conflict. Princeton University Press.

631 Bergsten J, Toy A, Nilsson AN. 2001. Intraspecific variation and intersexual correlation in 632 secondary sexual characters of three diving beetles (Coleoptera: Dytiscidae) Biological 633 Journal of the Linnean Society 73: 221-232. DOI: https://doi.org/10.100GJbjls.2001.054

634 Bicha W. 2018. Biodiversity of Mecoptera: Science and Society. Foottit R, Adler PH (Eds). 635 Insect Biodiversity: Science and Society, II. John Wiley \& Sons, Hoboken. p. 705-720. 
636 Bockwinkel G, Sauer KP. 1994. Resource dependence of male mating tactics in the 637 scorpionfly, Panorpa vulgaris (Mecoptera, Panorpidae). Animal Behaviour 47: 203-209. 638 DOI: https://doi.org/10.1006/anbe.1994.1023

639 Brennan PRL, Prum RO. 2012. The limits of sexual conflict in the narrow sense: new insights 640 from waterfowl biology. Philosophical Transactions of The Royal Society B: Biological 641 Sciences 367: 2324-2338. DOI: http://dx.doi.org/10.1098/rstb.2011.0284

642 Bussiére LF, Basit HA, Gwynne DT. 2005. Preferred males are not always good providers: 643 female choice and male investment in tree crickets. Behavioral Ecology 16: 223-231.

644 Byers GW, Thornhill R. 1983. Biology of the Mecoptera. Annual Review of Entomology 28: 645 203-228. DOI: https://doi.org/10.1146/annurev.en.28.010183.001223

646 Cheng FY. 1957. Descriptions of new Panorpidae (Mecoptera) in the collection of the 647 California Academy of Sciences. Memoirs of the College of Agriculture 5: 27-33.

648 Chou I, Ran RB, Wang SM. 1981. Studies on the classification of Chinese Mecoptera (I, II). 649 Entomotaxonomia 3: 1-18.

650 Cordero A., Andrés JA. 2002. Male coercion and convenience polyandry in a calopterygid 651 damselfly. Journal of Insect Science, 2: 14. DOI: http://dx.doi.org/10.1093/jis/2.1.14

652 Crampton GC. 1931. The Genitalia and Terminal Structures of the Male of the Archaic 653 Mecopteran Notiothauma reedi, compared with related Holometabola from the standpoint of 654 Phylogeny. Psyche 38: 1-21. DOI: http://dx.doi.org/10.1155/1931/28135

655 Ding H, Shih C, Bashkuev A, Zhao Y, Ren D. 2014. The earliest fossil record of Panorpidae 656 (Mecoptera) from the Middle Jurassic of China. ZooKeys 431: 79-92. DOI: 657 https://doi.org/10.3897/zookeys.431.7561

658 Eberhard WG. 2002. Physical Restraint or Stimulation? The Function(s) of the Modified 659 Front Legs of Male Archisepsis diversiformis (Diptera, Sepsidae). Journal of Insect Behavior 660 15: 831-850.

661 Eggert AK, Sakaluk SK. 1994. Sexual cannibalism and its relation to male mating success in 662 sagebrush crickets, Cyphoderris strepitans (Haglidae: Orthoptera). Animal Behaviour 47: $663 \quad 1171-1177$.

664 Engqvist L, Sauer KP. 2001. A life-history perspective on strategic mating effort in male 665 scorpionflies. Behavioral Ecology 13: 632-636. DOI: https://doi.org/10.1093/beheco/13.5.632 
666 Gao C, Ma NA, Hua BZ. 2016. Cerapanorpa, a new genus of Panorpidae (Insecta: 667 Mecoptera) with descriptions of three new species. Zootaxa 4158: 93-104. 668 http://doi.org/10.11646/zootaxa.4158.1.5

669 Ghislandi PG, Beyer M, Velado P, Tuni C. 2017. Silk wrapping of nuptial gifts aids cheating 670 behaviour in male spiders. Behavioral Ecology 28: 744-749. DOI: 671 https://doi.org/10.1093/beheco/arx028

672 Grimaldi DA, Engel MS. 2005. Evolution of the Insects. Cambridge University Press.

673 Grimaldi DA, Ross AJ. 2017. Extraordinary Lagerstätten in amber, with particular reference 674 to the Cretaceous of Burma. Fraser NC, Suess HD (Eds). Terrestrial Conservation 675 Lagerstätten: Windows into the Evolution of Life on Land. Dunedin Academic Press, 676 Edinburgh. p. 287-342.

677 Gwynne DT. 1984. Nuptial feeding behaviour and female choice of mates in Harpobittacus 678 similis (Mecoptera: Bittacidae). Journal of Australian Entomological Society 23: 271-276.

679 Han CS, Jablonski P. 2010. Male water striders attract predators to intimidate females into 680 copulation. Nature Communications 1: 52. https://doi.org/10.1038/ncomms1051

681 Handlirsch A. 1906-1908. Die fossilen Insecten und die Phylogenie der rezenten Formen. 682 Leipzig, Engelmann.

683 Hardwicke T. 1825. Description of the Cermatia longieornis and of three new insects from 684 Nepal. Transactions of the Linnean Society of London 14: 131-136.

685 Haug JT, Azar D, Ross A, Szwedo J, Wang B, Arillo A, Baranov V, Bechteler J, Beutel R, 686 Blagoderov V, Delclòs X, Dunlop J, Feldberg K, Feldmann R, Foth C, Fraaije RHB, Gehler 687 A, Harms D, Hedenäs L, Hyžny M, Jagt JWM, Jagt-Yazykova EA, Jarzembowski E, Kerp H, 688 Khine PK, Kirejtshuk AG, Klug C, Kopylov DS, Kotthoff U, Kriwet J, McKellar RC, Nel A, 689 Neumann C, Nützel A, Peñalver E, Perrichot V, Pint A, Ragazzi E, Regalado L, Reich M, 690 Rikkinen J, Sadowski EM, Schmidt AR, Schneider H, Schram FR, Schweigert G, Selden P, 691 Seyfullah LJ, Solórzano-Kraemer MM, Stilwell JD, van Bakel BWM, Vega FJ, Wang Y, 692 Xing L, Haug C. 2020. Comment on the letter of the Society of Vertebrate Paleontology 693 (SVP) dated April 21, 2020 regarding "Fossils from conflict zones and reproducibility of 694 fossil-based scientific data": Myanmar amber. Paläontologische Zeitschrift 94: 431695 437. DOI: https://doi.org/10.1007/s12542-020-00524-9 
696 Hrušková-Martišová M, Pekár S, Bilde T. 2010. Coercive copulation in two sexually 697 cannibalistic camel-spider species (Arachnida: Solifugae). Journal of Zoology 282: 91-99. 698 DOI: https://doi.org/10.1111/j.1469-7998.2010.00718.x

699 Hu GL, Yan G, Xu H, Hua BZ. 2015. Molecular phylogeny of Panorpidae (Insecta: Mecop700 tera) based on mitochondrial and nuclear genes. Molecular Phylogenetics and Evolution $\mathbf{8 5}$ : 701 22-31. DOI: https://doi.org/10.1016/j.ympev.2015.01.009

702 Hua BZ, Chou I. 1997. The Panorpidae (Mecoptera) of Funiu Mountain in Henan Province. 703 Entomotaxonomia 19: 273-278.

704 Kasiński JR, Kramarska R, Słodkowska B, Sivkov V, Piwocki M. 2020. Paleocene and 705 Eocene de pos its on the east ern mar gin of the Gulf of Gdańsk (Yantarny P-1 bore hole, 706 Kaliningrad region, Russia). Geological Quarterly 64: 29-53. DOI: 707 http://dx.doi.org/10.7306/gq.1513

708 Kimura K, Chiba S. 2015. The direct cost of traumatic secretion transfer in hermaphroditic 709 land snails: individuals stabbed with a love dart decrease lifetime fecundity. Proceedings of 710 the Royal Society B 282: 20143063. DOI: http://dx.doi.org/10.1098/rspb.2014.3063

711 Kock D, Engels S, Fritsche C, Sauer KP. 2009. Sexual coercion in Panorpa scorpionflies? 712 The function of the notal organ reconsidered. Behavioral Ecology 20: 639-643. DOI: 713 https://doi.org/10.1093/beheco/arp043

714 Krzemiński W, Soszyńska-Maj A. 2012. A new genus and species of scorpionfly (Mecoptera) 715 from Baltic amber, with an unusually developed postnotal organ. Systematic Entomology 37: 716 223-228. DOI: https://doi.org/10.1111/j.1365-3113.2011.00602.x

717 Kullmann H, Sauer KP. 2005. Life histories and mating system aspects of two Caucasian 718 scorpionfly species: Panorpa similis Esben-Petersen and Panorpa connexa Mac 719 Lachlan. Zoologischer Anzeiger 244: 1-9. DOI: https://doi.org/10.1016/j.jcz.2004.12.003

720 Latreille PA. 1805. Historie naturelle, générale et particulièr, des Crustacés et des Insectes, 721 13e. París.

722 LeBas N, Hockham LR. 2005: An invasion of cheats: the evolution of worthless nuptial gifts.

723 Current Biology 15: 64-67. DOI: https://doi.org/10.1016/S0960-9822(04)01021-8

724 Lehmann GUC. 2012. Weighing costs and benefits of mating in bushcrickets (Insecta: 725 Orthoptera: Tettigoniidae), with an emphasis on nuptial gifts, protandry and mate density. 726 Frontiers in Zoology 9: 19. DOI: https://doi.org/10.1186/1742-9994-9-19 
Li L, Shih C, Wang C, Ren D. 2017. A new fossil scorpionfly (Insecta: Mecoptera:

728 Holcorpidae) with extremely elongate male genitalia from northeastern China. Acta

729 Geologica Sinica - English Edition 91: 797-805. DOI: https://doi.org/10.1111/1755$730 \quad 6724.13310$

731 Liu X, Hayashi F, Lavine LC, Yang D. 2015. Is diversification in male reproductive traits 732 driven by evolutionary trade-offs between weapons and nuptial gifts? Proceedings of the 733 Royal Society B 282: 20150247. DOI: http://dx.doi.org/10.1098/rspb.2015.0247

734 McCartney J, Potter MA, Robertson AW, Heller KG, Gwynne DT. 2013. Chapter 2. Evidence 735 of natural and sexual selection shaping the size of nuptial gifts among a single bush-cricket 736 genus (Poecilimon; Tettigoniidae): An analysis of sperm transfer patterns. Geldani R, Davin 737 M Sexual Selection. Nova Science Publishers, Inc. p. 45-68.

738 MacLachlan R. 1877. Monographic Revision and Synopsis of the Trichoptera of the European 739 Fauna (1874-1880). London, John van Voorst.

740 Martynov, A. 1937. Liassic insects from Shurab and Kisyl-Kiya. Part 1. Various orders except 741 Blattodea and Coleoptera. Trudy Paleontologicheskogo Instituta Akademii Nauk SSSR 7: 1742232.

743 Miao Y, Wang JS, Hua BZ. 2018. Molecular phylogeny of the scorpionflies Panorpidae 744 (Insecta: Mecoptera) and chromosomal evolution. Cladistics 35: 1-16. DOI: 745 http://dx.doi.org/10.1111/cla.12357

746 Mickoleit G. 1971. Das Exoskelet von Notiothauma reedi MacLachlan, ein Beitrag zur 747 Morphologie und Phylogenie der Mecoptera (Insecta). Zeitschrift für Morphologie und 748 Ökologie der Tiere 69: 318-362.

749 Najarro M, Peñalver E, Pérez-de la Fuente R, Ortega-Blanco J, Menor-Salván C, Barrón E, 750 Soriano C, Rosales I, López del Valle R, Velasco F, Tornos F, Daviero-Gomez V, Gomez B, 751 Delclòs X. 2010. A review of the El Soplao amber outcrop, early Cretaceous of Cantabria 752 (Spain). Acta Geologica Sinica, English Edition 84: 959-976. DOI: https://doi.org/ 753 10.1111/j.1755-6724.2010.00258.x

754 Najarro M, Peñalver E, Rosales I, Pérez-de la Fuente R, Daviero-Gomez V, Gomez B, 755 Delclòs X. 2009. Unusual concentration of Early Albian arthropod-bearing amber in the 756 Basque-Cantabrian Basin (El Soplao, Cantabria, Northern Spain): palaeoenvironmental and 
757 palaeobiological implications. Geologica Acta 7: 363-387. DOI: https://doi.org/10.1344 $758 \quad / 105.000001443$

759 Neff BD, Svensson EI. 2013. Polyandry and alternative mating tactics. Philosophical 760 Transactions of the Royal Society B: Biological Sciences 368: 20120045. DOI: 761 https://doi.org/10.1098/rstb.2012.0045

762 Packard AS. 1886. A new arrangement of the orders of insects. American Naturalist 17: 932763945.

764 Parker GA. 1979. Sexual selection and sexual conflict. Blum MA, Blum NA (Eds). Sexual 765 selection and reproductive competition in insects. London: Academic Press. p. 123-166.

766 Petrulevičius J, Ren D. 2012. A new species of "orthophlebiidae" (Insecta: Mecoptera) from 767 the Middle Jurassic of Inner Mongolia, China. Revue de Paléobiologie 31: 311-315.

768 Preston-Mafham KG. 1999. Courtship and mating in Empis (Xanthempis) trigramma Meig., 769 E. tessellate F. and E. (Polyblepharis) opaca F. (Diptera: Empididae) and the possible 770 implications of 'cheating' behavior. Journal of Zoology 247: 239-246. DOI: 771 http://dx.doi.org/10.1111/J.1469-7998.1999.TB00987.X

772 Rostant WG, Fowler EK, Chapman T. 2020. Sexual Conflict Theory: Concepts and Empirical 773 Tests. Shackelford TK (Eds). The Sage Handbook of Evolutionary Psychology: Foundations 774 of Evolutionary Psychology. SAGE Publications. p. 241-259.

775 Sadowski JA, Moore AJ, Brodie ED. 1999. The evolution of empty nuptial gifts in a dance 776 fly, (Diptera: Empididae): bigger isn't always better. Behavioral Ecology and Sociobiology 777 45: 161-166. DOI: https://doi.org/10.1007/s002650050549

778 Sakaluk SK, Campbell MTH, Clark AP, Chadwick-Johnson J, Keorpes PA. 2004. 779 Hemolymph loss during nuptial feeding constrains male mating success in sagebrush crickets. 780 Behavioral Ecology 15: 845-849.

781 Shi G, Grimaldi DA, Harlow GE, Wang J, Yang M, Lei W, Li Q, Li X. 2012. Age constraint 782 on Burmese amber based on U-Pb dating of zircons. Cretaceous Research 37: 155-163. DOI: 783 http://dx.doi.org/10.1016/j.cretres.2012.03.014

784 Siva-Jothy MT 2006. Trauma, disease and collateral damage: conflict in cimicids. 785 Philosophical transactions of the Royal Society B 361: 269-275. 
Soszyńska-Maj A, Krzemiński W, Kopeć K, Cao Y, Ren D. 2018. Large Jurassic 788 scorpionflies - belonging to a new subfamily of the family Orthophlebiidae (Mecoptera). Annales Zoologici 68: 85-92. DOI: http://dx.doi.org/10.1080/08912963.2018.1564747

Soszyńska-Maj A, Krzemiński W, Kopeć K, Cao Y, Ren D. 2020. New Middle Jurassic fossils shed light on the relationship of recent Panorpoidea (Insecta, Mecoptera). Historical Biology 32: 1081-1097. DOI: https://doi.org/10.1080/08912963.2018.1564747 Stålhandske P. 2001. Nuptial gift in the spider Pisaura mirabilis maintained by sexual selection. Behavioral Ecology 12: 691-697. DOI: https://doi.org/10.1093/beheco/12.6.691

A. 2020. International https://doi.org/10.11646/palaeoentomology.3.3.1

Tillyard RJ. 1933. The Panorpoid Complex in the British Rhaetic and Lias. Britain Museum Fossil Insects 3, 1-79.

800 Thornhill R. 1976. Sexual selection and nuptial feeding behaviour in Bittacus apicalis 801 (Insecta: Mecoptera). American Naturalist 110: 529-548.

802 Thornhill R. 1979. Male and female sexual selection and the evolution of mating strategies in 803 insects. Blum MS, Blum NA (Eds). Sexual Selection and Reproductive Competition in 804 Insects. Academic Press, New York. p. 81-121.

805 Thornhill R. 1980. Rape in Panorpa scorpionflies and a general rape hypothesis. Animal 806 Behaviour 28: 52-59. DOI: https://psycnet.apa.org/doi/10.1016/S0003-3472(80)80007-8

807 Thornhill R. 1990. The study of adaptation. Bekoff M, Jamieson D (Eds). Adaptation 808 Interpretation and Explanation in the Study of Behaviour. Boulder: Westview Press, vol 2, 809 chap. 2.

810 Tong X, Hua BZ. 2019. Nuptial feeding and genital coupling of Neopanorpa scorpionflies 811 (Insecta: Mecoptera: Panorpidae) with notal organs of various lengths. Contributions to 812 Zoology 88: 498-512. DOI: https://doi.org/10.1163/18759866-20191409

813 Thornhill R, Sauer KP. 1991. The notal organ of the scorpionfly (Panorpa vulgaris): an 814 adaptation to coerce mating duration. Behavioral Ecology 2: 156-164. DOI: 815 https://doi.org/10.1093/beheco/2.2.156 
816 Tong X, Jiang L, Hua BZ. 2017. A unique mating pattern of Panorpodes kuandianensis 817 (Mecoptera: Panorpodidae). Contributions to Zoology 86: 229-237. DOI: 10.1163/1875986608603003

819 Tong X, Zhong W, Hua BZ. 2018. Copulatory mechanism and functional morphology of 820 genitalia and anal horn of the scorpionfly Cerapanorpa dubia (Mecoptera: 821 Panorpidae). Journal of Morphology 279:1532-1539. DOI: https://doi.org/10.1002/ 822 jmor.20903

823 Wang JS. 2020. Phylogeny and Taxonomy of the World Panorpidae (Mecoptera). 824 Dissertation. College of Plant Protection Northwest A\&F University, Shaanxi, China.

825 Wang JS, Hua BZ. 2018a. A Color Atlas of the Chinese Mecoptera. Henan Science and Tech826 nology Press, Zhengzhou.

827 Wang M, Hua BZ. 2018b. A new species of Neopanorpa with an extremely long notal organ 828 from Sichuan, China (Mecoptera, Panorpidae). ZooKeys 750: 131-140. DOI: 829 https://doi.org/10.3897/zookeys.750.23486

830 Wang JS, Hua BZ. 2019a. Megapanorpa, a new genus with a single anal horn in males from

831 Oriental China (Mecoptera: Panorpidae). Entomological Science 22: 64-79. DOI: 832 https://doi.org/10.1111/ens.12336

833 Wang JS, Hua BZ. 2019b. Taxonomy of the genus Neopanorpa van der Weele, 1909 834 (Mecoptera, Panorpidae) from the Oriental Region, with the description of two new species. 835 European Journal of Taxonomy 543: 1-17. DOI: http://dx.doi.org/10.5852/ejt.2019.543

836 Wang JS, Hua BZ. 2020. Taxonomic revision and phylogenetic analysis of the enigmatic 837 scorpionfly genus Leptopanorpa MacLachlan (Mecoptera: Panorpidae). Journal of Zoological 838 Systematics and Evolutionary Research 58: 900-928. DOI: https://doi.org/10.1111/jzs.12363

839 Wang JS, Hua BZ. 2021. Morphological phylogeny of Panorpidae (Mecoptera: Panorpoidea). $840 \quad$ Systematic Entomology 43: 526-557. DOI: https://doi.org/10.1111/syen.12474

841 Wang Q, Shih C, Ren D. 2013. The Earliest Case of Extreme Sexual Display with 842 Exaggerated Male Organs by Two Middle Jurassic Mecopterans. PLoS ONE 8,e71378. DOI: 843 https://doi.org/10.1371/journal.pone.0071378

844 van der Weele HW. 1909. Mecoptera and Planipennia of Insulinde with biological notes from 845 Edw. Jacobson. Notes Leyden Museum 31: 1-100. 
846 Willmann R. 1989. Evolution und phylogenetisches System der Mecoptera. Abhandlungen 847 der Senckenberg Gesellschaft für Naturforschung 544: 1-153.

848 Willmann R, Novokschonov V. 1998. Neue Mecopteren aus dem oberen Jura von Karatau 849 (Kazachstan) (Insecta: 'Orthophlebiidae'). Paläontologische Zeitschrift 72: 281-298.

850 Yamane T, Okada K, Nakayama S, Miyatake T. 2011. Dispersal and ejaculatory strategies 851 associated with exaggeration of weapon in an armed beetle. Proceedings of the Royal Society 852 B 277: 1705-1710. DOI: https://doi.org/10.1098/rspb.2009.2017

853 Zhang Y, Shih PJM, Wang Y, McNamara ME, Shih C, Dong R, Gao T. 2021. Jurassic 854 scorpionflies (Mecoptera) with swollen first metatarsal segments suggesting sexual 855 dimorphism. BMC Ecology and Evolution 21: 47. DOI: https://doi.org/10.1186/s12862-021$856 \quad 01771-3$

857 Zhong W, Hua BZ. 2013. Mating behaviour and copulatory mechanism in the scorpionfly 858 Neopanorpa longiprocessa (Mecoptera: Panorpidae). PLoS ONE 8: e74781. DOI: 859 https://doi.org/10.1371/journal.pone.0074781

860 Zhong W, Ding G, Hua BZ. 2014. The role of male's anal horns in copulation of a scorpion861 fly. Journal of Zoology 295: 170-177. DOI: https://doi.org/10.1111/jzo.12194

862 Zhong W, Qi ZY, Hua BZ. 2015. Atypical mating in a scorpionfly without a notal organ. 863 Contributions to Zoology 84: 305-315. DOI: http://dx.doi.org/10.1163/18759866-08404003

865 Figure captions

866 Figure 1. Baltipanorpa oppressiva sp. nov. (Panorpidae) from Baltic amber (middle Eocene), 867 holotype MP/2711. A-B, habitus, photograph of preserved portion (A) and explanatory 868 drawing (B), with genital bulb in ventrolateral view magnified; C-E, notal organ: fully869 clasped clamp formed by notal and postnotal organs (C), teeth inside the notal-postnotal 870 clamp (D), detail of terminal clasp (E); F, life reconstruction of entire specimen (head and 871 thorax, missing in this species, based on habitus of congeneric Baltipanorpa damzeni). G, 872 forewing. H, hind wing (same scale in both wings). Abbreviations: Ep, epandrium; HP, horn873 like process; Hv, hypovalve; NO, notal process; PO, postnotal process; Gs, gonostylus; Gcx, 874 gonocoxite. Red colour: notal process.

876 Figure 2. Burmorthophlebia multiprocessa gen. et sp. nov. (Orthophlebiidae) from Kachin 877 amber, Myanmar (Late Cretaceous), holotype MP/3721. A, amber piece with habitus in lateral 
view; B, life reconstruction; C, forewing; D, hind wing, partially reconstructed; E-F, abdomen in lateral view, explanatory drawing (E) and photograph (F); G, detail of head in lateral view, antennae and rostrum; $\mathrm{H}$, notal process and postnotal areas (on tergites III and IV, respectively). Abbreviations: AH, anal horns; PA1, PA2, postnotal areas 1, 2; other symbols as in Fig. 1.

Figure 3. Photomicrographs of Cantabra soplao gen. et sp. nov. (Cantabridae fam. nov.), from El Soplao amber, Spain (Early Cretaceous), holotype CES-437. A, ventral and lateral habitus, respectively; B-C, head, frontoventral view (B), lateral view (C); D, setae on anal area of forewing; E, postnotal organ seen in ventrolateral view (head is to the left), morphology distorted due to the skewed view; F, genital bulb in ventral view; $G$, detail of gonostylus, showing its inner denticles. Abbreviations: OB, ocellar bristles; PO, postnotal organ.

Figure 4. Explanatory drawings of Cantabra soplao gen. et sp. nov. (Cantabridae fam. nov.) from El Soplao amber, Spain (Early Cretaceous), holotype CES-437. A, right forewing; B, right hind wing (same scale for both wings); C-D, reconstruction of abdomen in lateral view, with genital bulb shown in ventral view (C); inset (arrow) shows the genital bulb expanded, with elements tagged (D); E, life reconstruction, in resting position. Notal organ not visible in holotype and thus not depicted for caution. Length of antennae and rostrum are conjectural; morphology of legs is based on the preserved left foreleg, which is mostly complete. Abbreviations: Bp, basal process; Pm, parameres; other symbols as in Fig. 1.

Figure 5. Spatial coupling between short male notal organs and female (fore)wings during mating in extant and extinct Mecoptera. A-B, Panorpa amurensis MacLachlan, 1872 (Recent): A, photograph of notal organ in male, and diagram cross section through the notal and postnotal processes with anterior fold of female forewing entrapped; B, photograph and diagram of anterior fold in female forewing; C-D, Orthophlebia heidemariae Willmann and Novokschonov, 1998 (Late Jurassic): habitus (C) and explanatory drawing (D; inset showing notal-postnotal system magnified); E, Burmorthophlebia multiprocessa, gen. et sp. nov (Late Cretaceous): diagram of abdominal modifications (bottom) and hypothetical spatial coupling between male notal organ and female wing (top). Abbreviations: SP, small process (tergite VII); other as in Figs 1, 2. Colour legend of cross section through veins: black circle, C (Costa); blue circle, Sc (Subcosta); red circle, R1 (1st radial vein); red line, wing membrane. 
913 Figure 6. Spatial coupling between long male notal organs and female (fore)wings during 914 mating in extant and extinct Mecoptera. A-D, Neopanorpa longistipitata Wang and Hua, 9152018 (Recent): A, photograph of mating couple; inset (arrow) shows notal and hypovalves 916 connection magnified; B, diagram of mating couple (notal organ depicted in red); C, 917 photograph of male abdomen in lateral view; D, diagram of coupling mechanism between

918 male notal organ and genital bulb; E, F, spatial coupling diagram between male notal919 postnotal clip clasping the female wing in two species of Baltipanorpa (Eocene): B. damzeni 920 (E); B. oppressiva sp. nov. (F). Abbreviations as in Figs 1, 2, 4, 5.

Figure 7. Male abdominal modifications in extinct and extant Panorpoidea on a time scale: A, 923 Orthophlebia heidemariae Willmann and Novokschonov, 1998 (Orthophlebiidae); B, 924 Cantabra soplao gen et sp. nov. (Cantabridae fam. nov.); C, Burmorthophlebia multiprocessa 925 gen. et sp. nov. (Orthophlebiidae); D, Baltipanorpa damzeni Krzemiński and Soszyńska-Maj, 9262012 (Panorpidae); E, Baltipanorpa oppressiva sp. nov. (Panorpidae); F-I, some examples of 927 extant Panorpidae species: F, Leptopanorpa linyejiei Wang and Hua, 2018; G, Leptopanorpa 928 jacobsoni (van der Weele, 1909); H, Neopanorpa longistipitata Wang and Hua, 2018; I, 929 Panorpa jinhuaensis Wang, Gao and Hua, 2019. Notal processes depicted in red. Drawings 930 not at same scale.

932 Figure 8. Geographical provenance of amber specimens studied herein. The two white stars 933 represent Cretaceous localities (El Soplao amber, Spain; Kachin amber, Myanmar); the 934 yellow star an Eocene deposit (Baltic amber).

936 Supplementary File 1. Spatial match between the space created by the clasped notal and 937 postnotal processes (NO-PO) and the anterior valley fold (from Costa to R1, measured across 938 wing) of the wing in some recent panorpids. T5, T6, tergites 5, 6. Measurements are 939 approximate, based on scale bars in published figures as specified.

941 Supplementary File 2. Remarks on the abdomen of fossil Panorpoidea. AH, anal horn; NO, 942 notal organ; PA, postnotal area; PO, postnotal organ; A5, A6, abdominal segments 5, 6. 

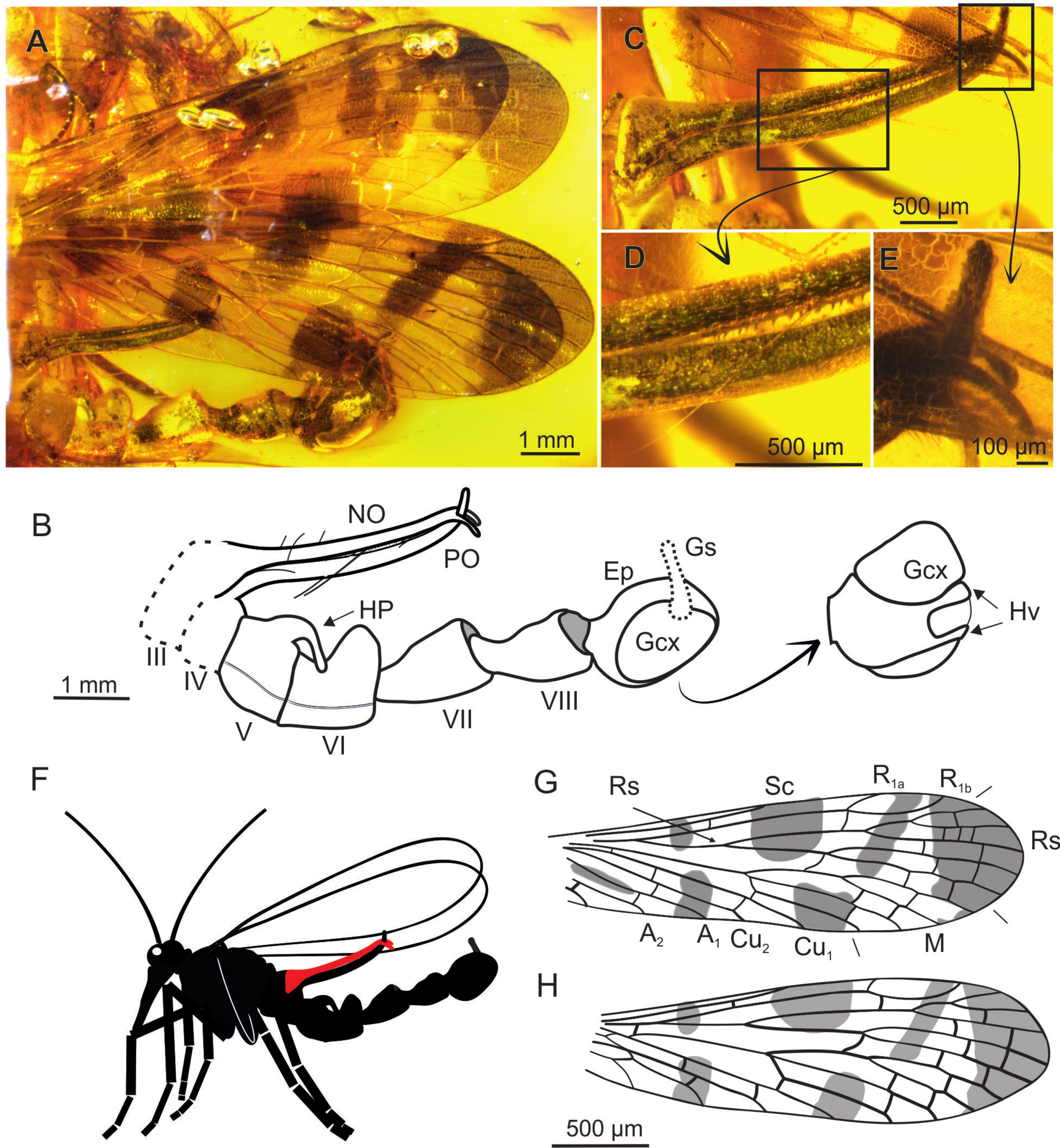


\section{A}

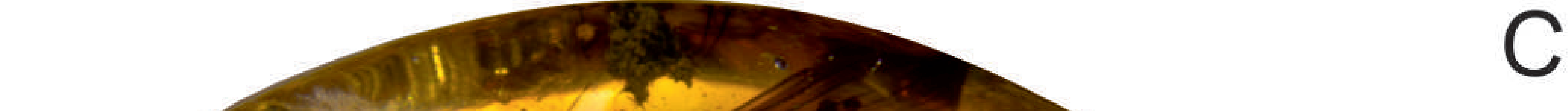

B
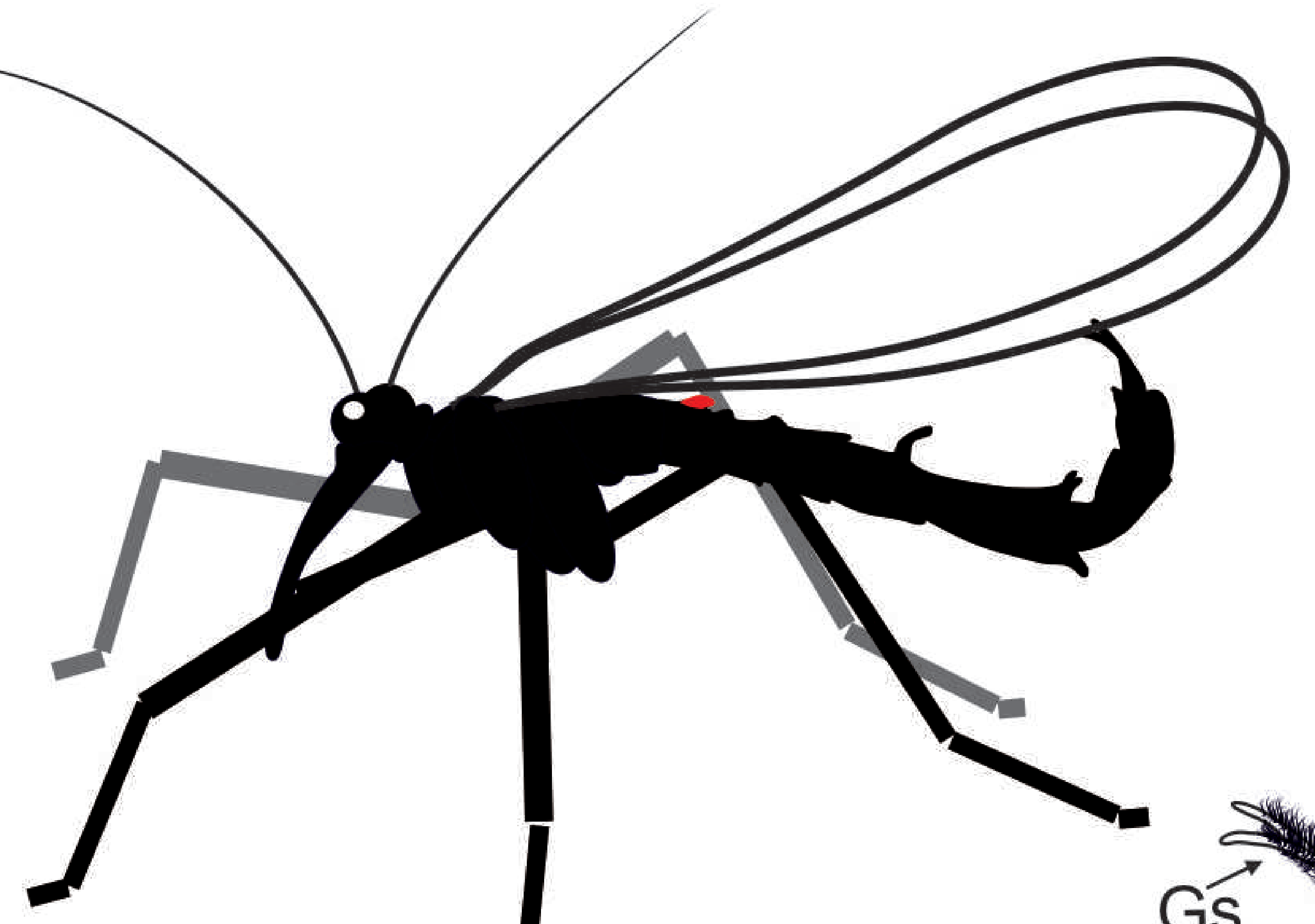

$2 \mathrm{~mm}$

D

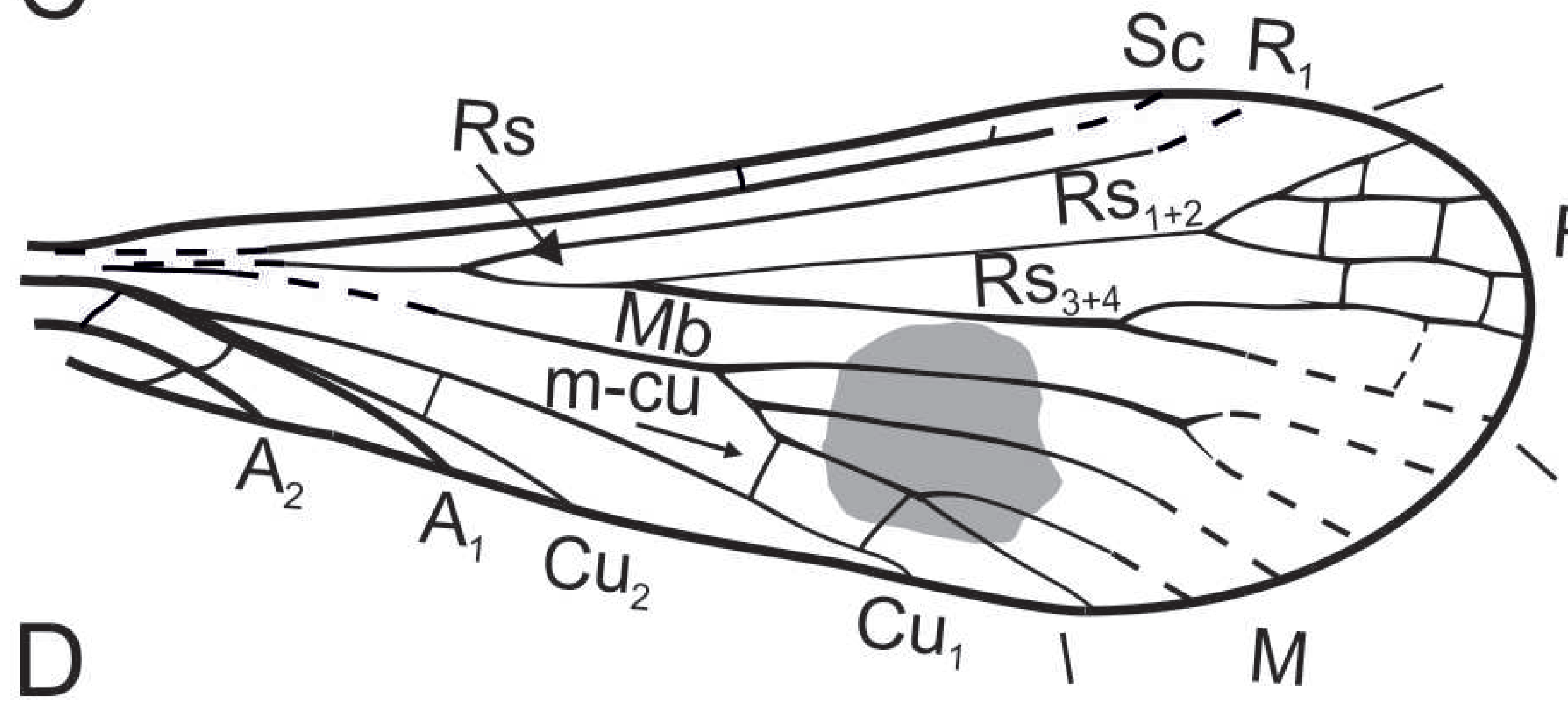

$1 \mathrm{~mm}$
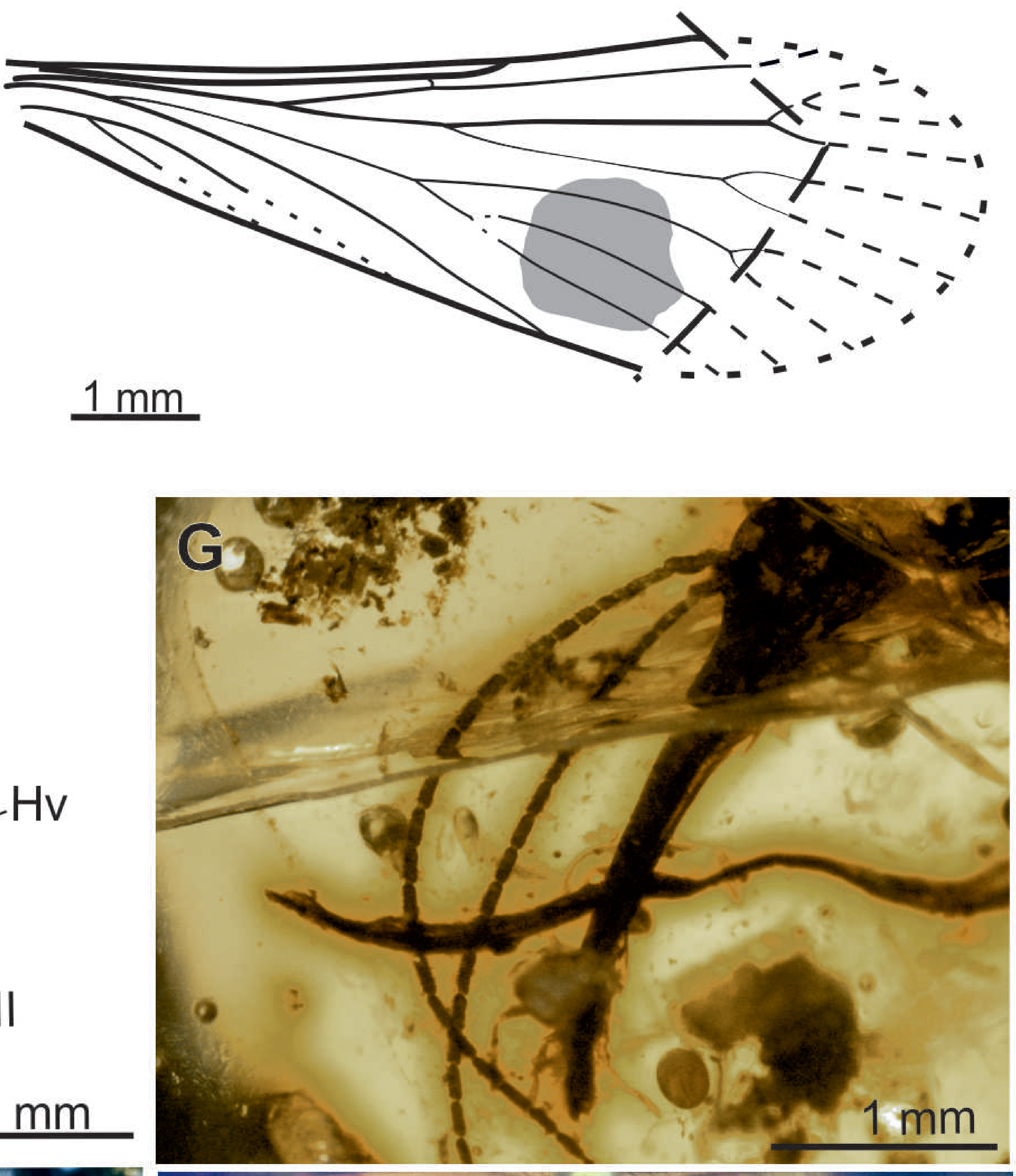

$\mathrm{H}$

I. $3: 2$

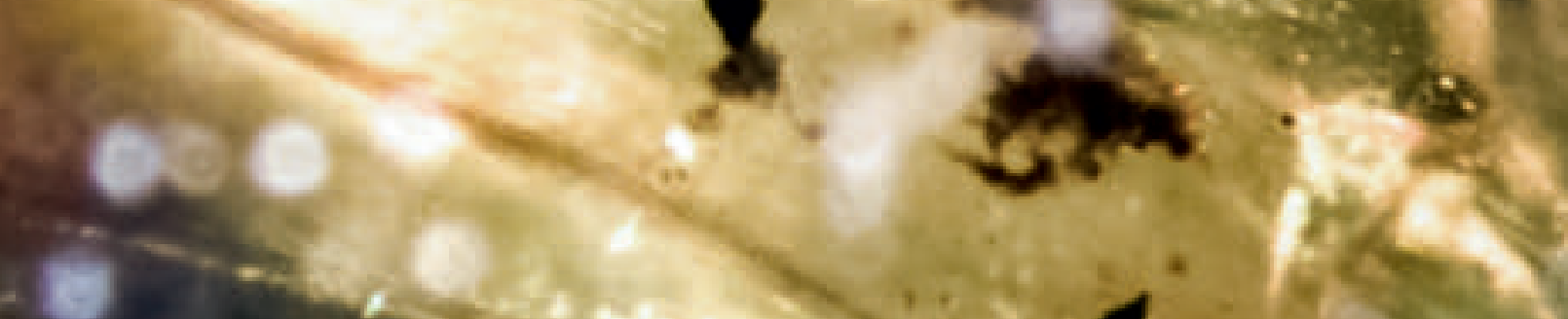

$1 \mathrm{~mm}$

F

$=$

NO

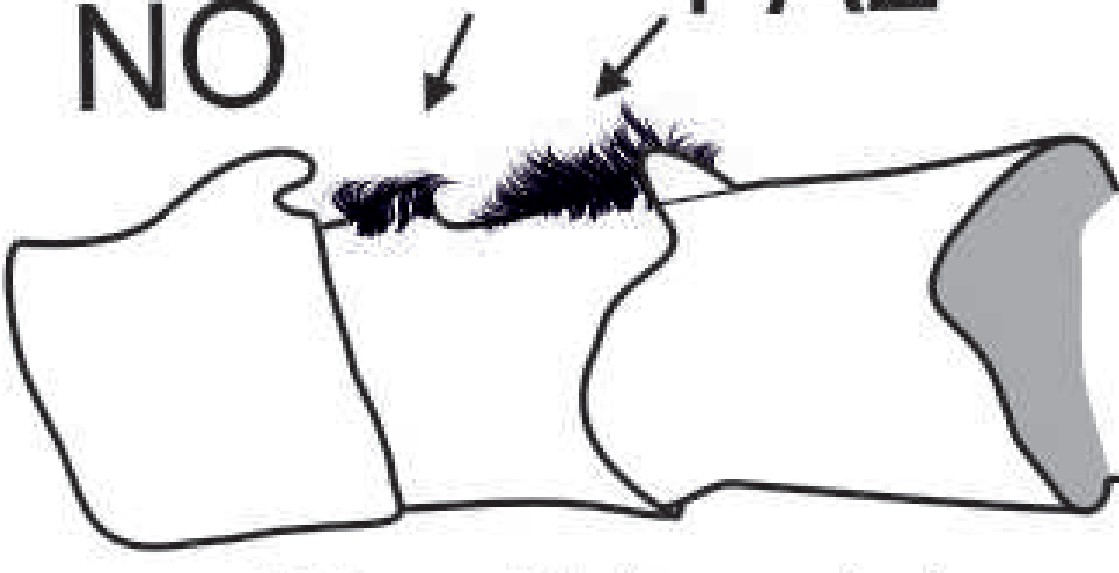

III IV V VI

VII

(2)

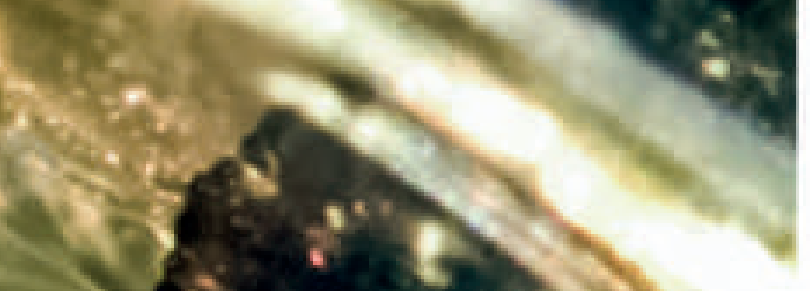

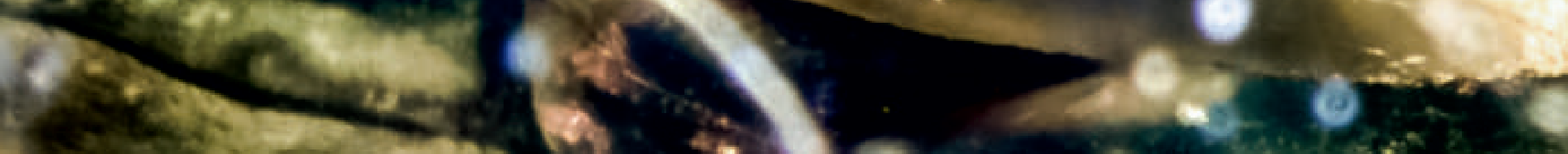
Shescis

VI . r

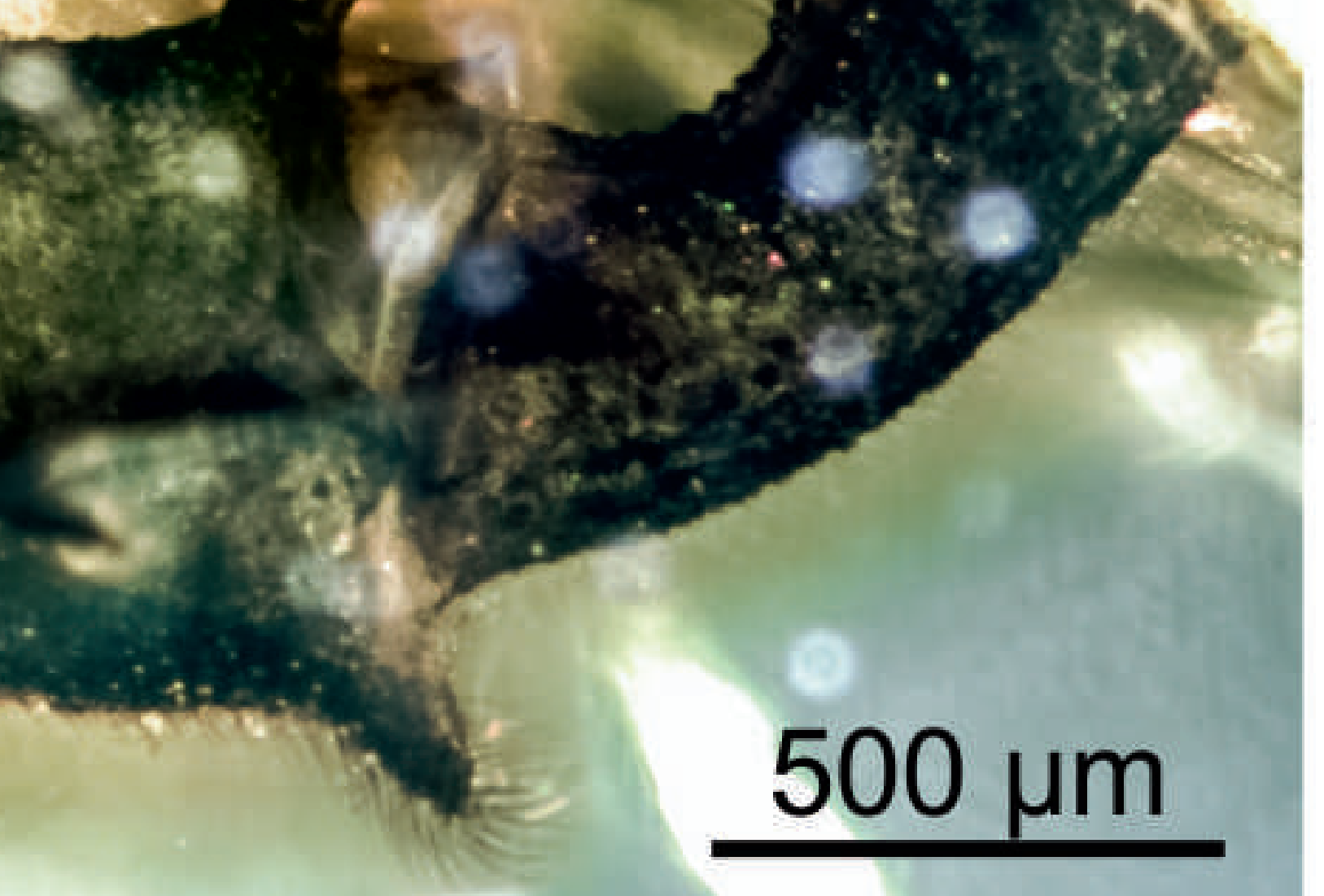

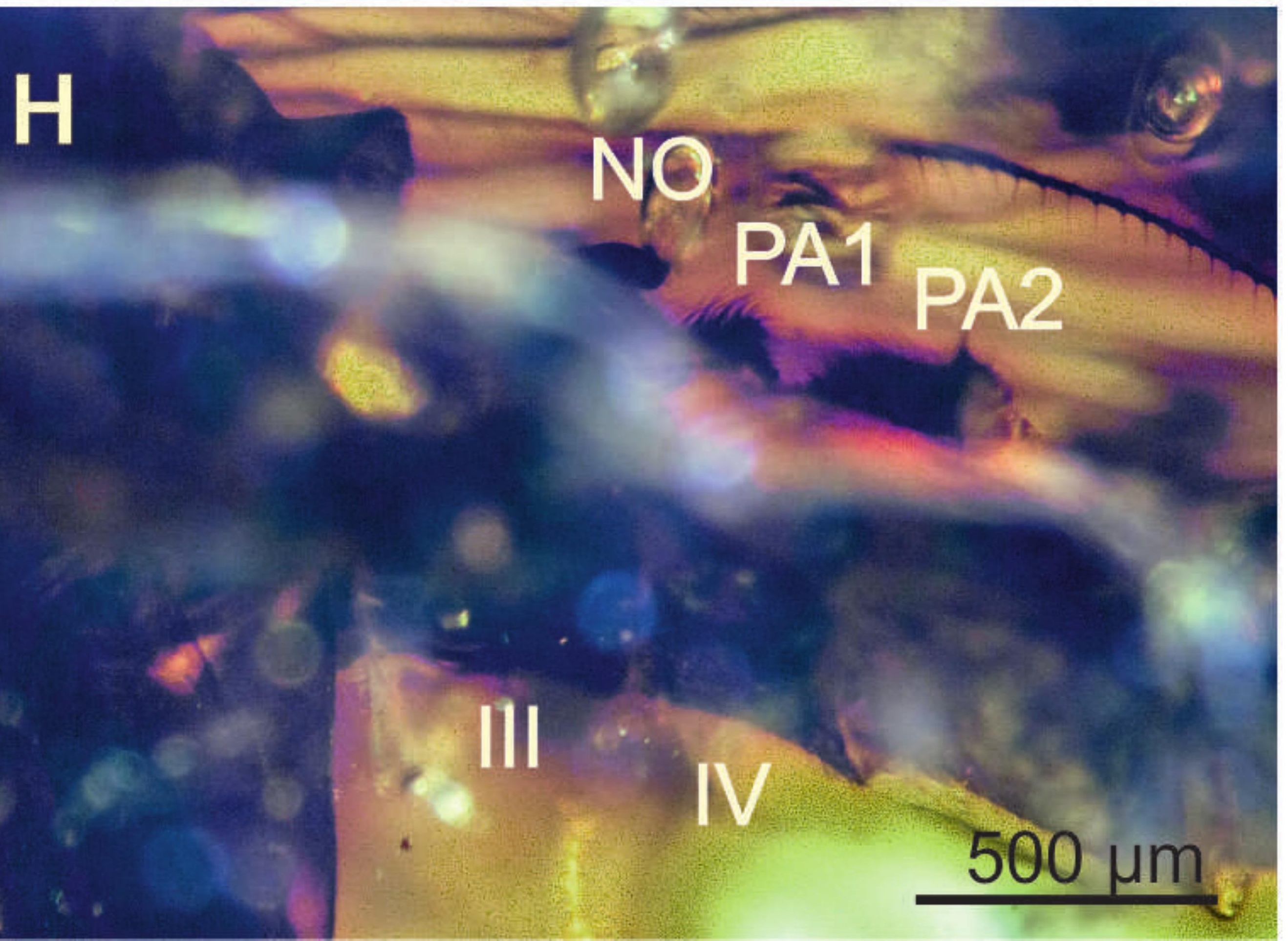




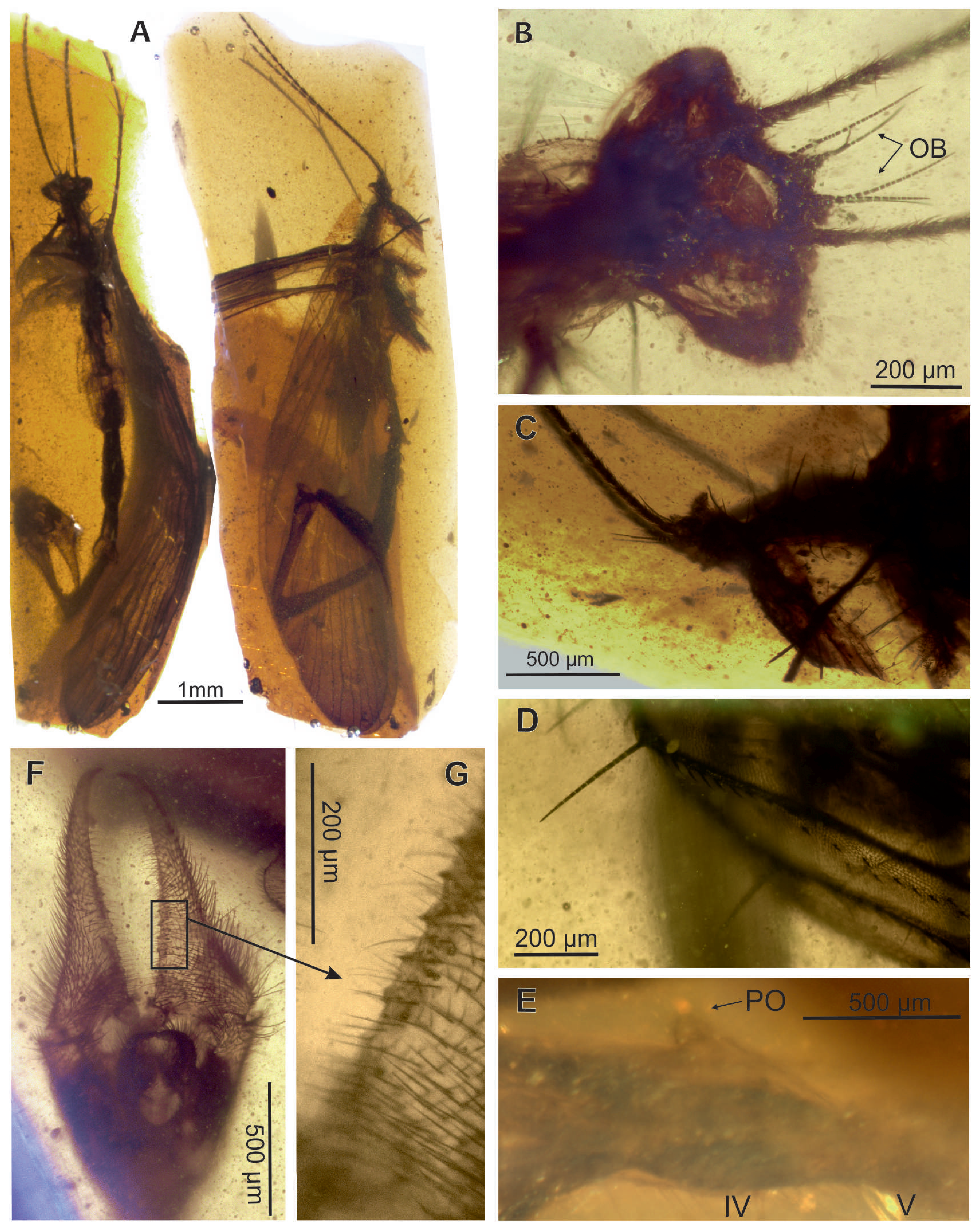




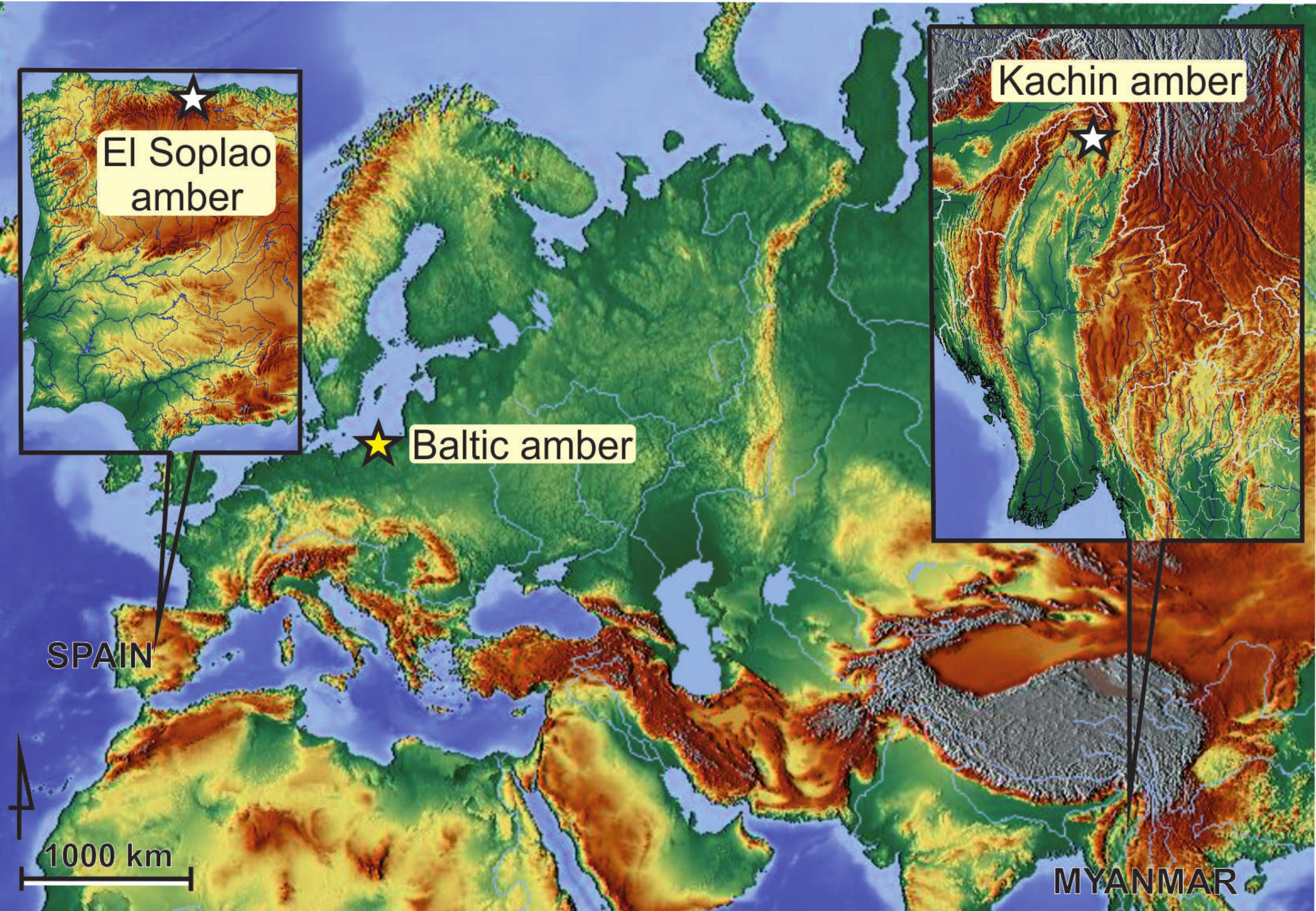

